\title{
Ultraviolet-induced fluorescence for plant monitoring: present state and prospects
}

\author{
Zoran G. Cerovic ${ }^{a}$, Guy Samson ${ }^{\mathrm{b}}$, Fermín Morales ${ }^{\mathrm{c}}$, Nicolas Tremblay ${ }^{\mathrm{d}}$, Ismaël Moya ${ }^{\mathrm{a}}$ \\ a Groupe photosynthèse et télédétéction, LURE/CNRS, Bât 203, centre universitaire Paris-Sud, B.P. 34, 91898 Orsay cedex, France

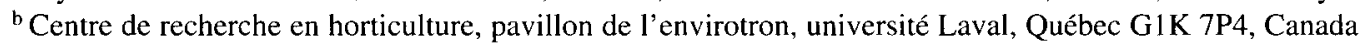 \\ ${ }^{c}$ Department of Plant Nutrition, Experimental Station of Aula Dei, Apartado 202, 50080 Zaragoza, Spain \\ ${ }^{\mathrm{d}}$ Centre de recherche et développement en horticulture, 430 Gouin, St-Jean-sur-Richelieu, Québec J3B 3E6, Canada
}

(Received 15 March 1999; accepted 12 August 1999)

\begin{abstract}
UV excitation of green leaves induces two distinct, fundamentally different, but still complementary types of fluorescence: a blue-green fluorescence in the $400-630 \mathrm{~nm}$ range and the chlorophyll $a$ fluorescence in the red to farred region $(630-800 \mathrm{~nm})$ of the spectrum. The relative intensities of these two types of fluorescence are highly sensitive to intrinsic leaf properties and environmental factors. Therefore, fluorescence emission spectra induced by UV radiation can be considered as a complex fluorescence signature that can reveal much about the physiological state of the plant. UV-induced fluorescence of leaves provides us with information on photosynthesis, primary photochemical reactions and chlorophyll content, and also on the presence and accumulation of the product of the secondary metabolism and the redox state of the cell. In this review we pay particular attention to the present and potential application of these signals to active remote sensing of vegetation, i.e. fluorosensing. (C) 1999 Inra/Éditions scientifiques et médicales Elsevier SAS.)
\end{abstract}

chlorophyll fluorescence / blue-green fluorescence / ultraviolet radiation / fluorescence lidar / remote sensing

Résumé - Fluorescence induite par le rayonnement ultraviolet pour le suivi de la végétation : état actuel et perspectives. L'excitation de feuilles vertes dans l'ultraviolet induit deux types de fluorescence distinctes, fondamentalement différentes, mais complémentaires : la fluorescence bleu-verte dans la région 400-630 nm et la fluorescence chlorophyllienne dans la partie rouge-infra-rouge du spectre. Les intensités relatives de ces deux types de fluorescence sont très sensibles aux propriétés intrinsèques des feuilles et aux facteurs de l'environnement. Par conséquent, les spectres d'émission de fluorescence induite par le rayonnement ultraviolet peuvent être considérés comme des signatures complexes qui renseignent sur l'état physiologique de la plante. La fluorescence des feuille induite par l'UV nous informe sur la photosynthèse, les réactions primaires photochimiques et la teneur en chlorophylle, et aussi sur l'accumu-

Communicated by Gérard Guyot (Avignon, France)

* Correspondence and reprints

cerovic@lure.u-psud.fr 
lation des produits du métabolisme secondaire ainsi que sur l'état rédox de la cellule. Dans cet article, nous nous sommes particulièrement intéressés à l'application de ces signaux à la télédétection active de la végétation, le " fluorosensing ». (C) 1999 Inra/Éditions scientifiques et médicales Elsevier SAS.)

\section{fluorescence chlorophyllienne / fluorescence bleu-verte / rayonnement ultraviolet / lidar de fluorescence / télédétection}

\begin{abstract}
Abbreviations, symbols and acronyms: BF, blue fluorescence; $\mathrm{BGF}$, blue-green fluorescence; Chl, chlorophyll; ChlF, chlorophyll fluorescence; DOM, dissolved organic mater; EEM, excitation-emission matrix; FGVI, fluorescence global vegetation index; FIS, fluorescence imaging systems; FLD, Fraunhofer line discriminator; FLIDAR, fluorescence LIDAR; $F_{m}$, maximum ChIF level; $F_{0}$, minimal ChlF level; $F_{p}$, ChlF at the peak of the fluorescence induction curve; $\mathrm{FRF}$, far-red fluorescence; $\mathrm{F}_{s}$, stationary ChlF level; $\mathrm{F}_{v}$, variable ChlF; FWHM, full width at half maximum; GF, green fluorescence; LASFLEUR, laser fluorescence Europe; LIDAR (lidar), light detection and ranging; LIF, laser-induced fluorescence; NDVI, normalized difference vegetation index; OMA, optical multichannel analyzer; PAM, pulse amplitude modulation; PSI, photosytem I; PSII, photosytem II; $\mathrm{Q}_{\mathrm{A}}$, 'primary' quinone acceptor of PSII; qN, non-photochemical quenching; qP, photochemical quenching; QSEU, quinine sulphate equivalent units; RF, red fluorescence; RFI, relative fluorescence intensities; $\tau$ LIDAR, fluorescence lifetime-LIDAR; $\tau_{\mathrm{m}}$, maximal ChlF lifetime; $\tau_{o}$, minimal ChlF lifetime.
\end{abstract}

\section{Introduction}

In recent years, UV-induced fluorescence from plants has emerged as a sensitive and specific tool for the remote sensing (fluorosensing) of vegetation. Several studies have indicated that UVinduced fluorescence possesses a large potential to assess accurately the physiological state of plants and to detect precociously the impacts of environmental stress on them [20, 94]. Fluorosensing may therefore have important applications in plant biology; namely in plant ecophysiology, agriculture and forestry. This review will present the physiological basis for such potential applications by discussing first the molecular and structural leaf properties responsible for the UV-induced plant fluorescence and then the environmental factors affecting UV-induced fluorescence emission spec- tra via their primary effects on the intrinsic characteristics of leaves. We shall also present the different spectroscopic techniques available for fluorosensing and the most promising applications of $\mathrm{UV}$-induced fluorescence in plant sciences.

Different aspects of the use of blue and red fluorescence for remote sensing of vegetation were treated in a review by Moya et al. [120], and more recently, other aspects were comprehensively described in three reviews by the Karlsruhe group $[20,94,104]$. General treatment on the use of chlorophyll fluorescence in vivo can be found [131, 141, 142]. In this context, two specialized reviews $[4,112]$ dedicated to the application of chlorophyll fluorescence to forestry should be mentioned. Information on fluorosensing can also be found in monographs published as proceedings of meetings on fluorosensing $[31,95]$ or more generally on vegetation stress [96]. The series of Proceedings of the Colloquia of Physical Measurements and Signatures in Remote Sensing, where fluorosensing has an ever increasing presence, can also be a useful source $[65,66]$.

The present review will consider only the plant fluorescence induced by UV excitation which might be, for eye safety reasons, the only practically applicable active fluorosensing technique for agricultural and environmental monitoring. The international safety regulation for the use of lasers, has favoured the use of UV lasers for remote sensing, mainly owing to high eye sensitivity for visible light [64]. For instance, the permissible energy flux for pulsed beams is ten thousand times larger below $400 \mathrm{~nm}$ than above this threshold wavelength, which delimits the visible region from UVA (CEI publication no. 825) [48].

As depicted in figure 1, vegetation fluorosensing originates from the fusion of different techniques specific to remote sensing and plant biology 


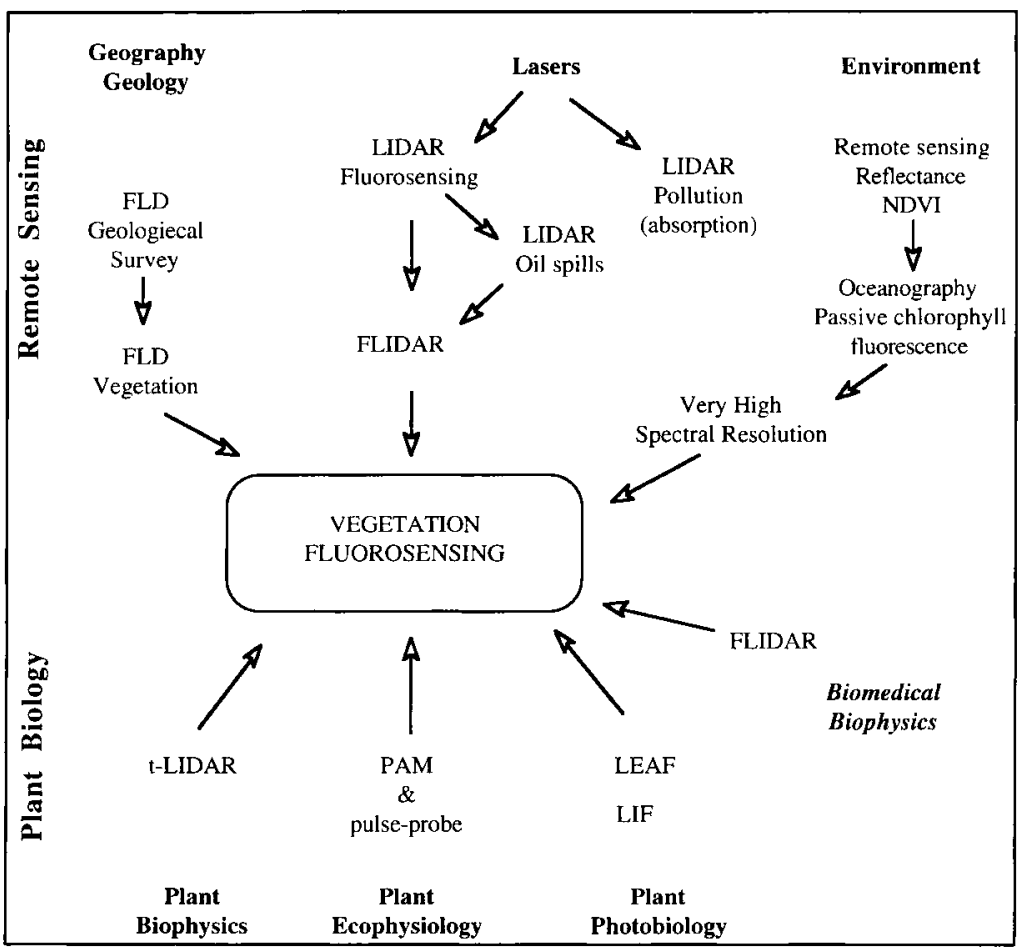

Figure 1. Origins of vegetation fluorosensing. Vegetation fluorosensing is emanating mainly from two domains of research, which are quite distinct. First, lidars were developed for active remote sensing in geology and for pollution monitoring and subsequently applied to vegetation. On the other hand, plant ecophysiology, biophysics and photobiology, all used ChlF extensively and developed lidar technology to move from cell and leaf to canopy level research. In addition, lasers set-ups developed for biomedical research and medical practice were soon adapted for work on plants, which have the homologous demands as human tissues (front-face configuration). Finally, with the development of very high spectral resolution, fluorescence is starting to gain in importance even in passive remote sensing of vegetation.

research. The most important contribution was the development of lidars (light detection and ranging), which use powerful lasers as excitation source [84]. Originally developed for phytoplankton [79] and oil spill detection [124], fluorescence lidars (FLIDAR) were used primarily for oceanographic survey [74], but were applied also to terrestrial vegetation [75]. The monitoring of chlorophyll and blue-green fluorescence of terrestrial vegetation has its equivalent in oceanography in the use of chlorophyll fluorescence to estimate phytoplankton, and in the use of UV-induced blue fluorescence to estimate dissolved organic mater (DOM). Chlorophyll fluorescence has also been detected at distance by passive devices, which can distinguish it from the plant reflectance signal using the Fraunhofer line discrimination principle (reviewed in [120]). The second most important contribution to vegetation fluorosensing came from plant sciences, where there was a need for non-destructive estimation of the productivity and the physiological state of vegetation. Dedicated fluorosensors were developed first in the laboratory, then for out- door use, to finish with dedicated lidars. Plant physiology laboratories also contributed to the understanding of fluorescence signals emitted by plants and the interaction of radiation and leaves. In Europe, these different approaches to vegetation fluorosensing were co-ordinated for several years through an EUREKA project (EU380, LASFLEUR, LASer FLuorescence EURope) aiming to develop a new airborne lidar [64].

\section{Fluorescence signatures}

UV excitation of a green leaf induces two distinct, fundamentally different but still complementary types of fluorescence: a blue-green fluorescence in the 400-630 $\mathrm{nm}$ range and the chlorophyll $a$ fluorescence in the red to far-red region $(630-800 \mathrm{~nm})$ of the spectrum. The relative intensities of these two types of fluorescence are highly sensitive to intrinsic leaf properties and environ- 
mental factors. Therefore, fluorescence emission spectra induced by UV light can be considered as a complex fluorescence signature that can reveal much about the physiological state of the plant.

A typical UV-A-induced fluorescence spectrum of leaves has three maxima and a shoulder (figure 2) which can be more or less pronounced. These maxima have variable amplitude depending on leaf origin: plant species, age, side of the leaf, size of the analysed area (anatomy), past and present stresses. For example, pea leaves (Pisum sativum L.) whose cell walls are known to be non-fluorescent [71], have much smaller blue-green fluorescence than sugar beet leaves (Beta vulgaris L.), whose cell walls are fluorescent because of the presence of esterified ferulic acid [71]. Accordingly, the blue-green to red fluorescence ratio is much larger in beet than pea leaves (figure 2). In figure 2 the absorption spectrum of a total methanolic extract of a leaf is also shown. It can be compared to the individual absorption spectra of potential fluorophores or absorbers present in leaves, shown in figure 3 . The prominent feature in the spectrum of the extract is the presence of chlorophyll, responsible for the red fluorescence of leaves, and carotenoids and flavonols, in the UV part of the spectrum, which do not fluoresce, but can screen the excitation of blue fluorescing compounds (see below).

\subsection{Fluorescence emission bands}

When a large-band detection of fluorescence is used (FWHM $>20 \mathrm{~nm}$ ), these spectral features are named blue (BF), green (GF), red (RF) and far-red (FRF) fluorescence (figure 2) (table I). The red and far-red fluorescence taken together are also called chlorophyll fluorescence (ChlF), because chlorophyll $a(\mathrm{Chl})$ is the only fluorophore present in leaves with emission in this part of the spectrum, chlorophyll $b$ transferring all its excitation to chlorophyll $a$ in vivo. Sometimes the far-red maxi-

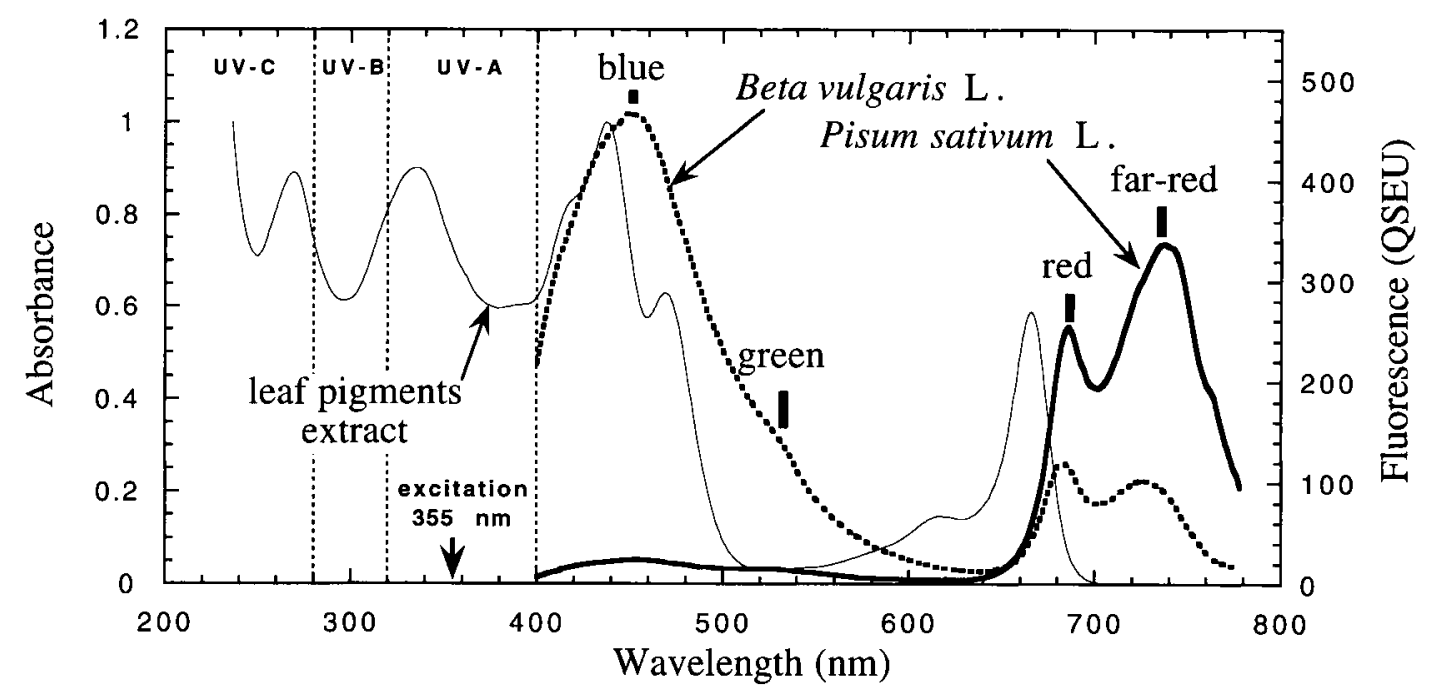

Figure 2. UV-excited fluorescence spectra of leaves with characteristic emission bands. Maxima of fluorescence emission spectra of adaxial sides of pea and sugar beet leaves are indicated. Spectra are superimposed on the absorption spectrum of a methanolic extract of leaves. Fluorescence spectra were measured on the FLU3 set-up of the SA4 line of Super-ACO storage ring at LURE in Orsay [30, $60]$. They were excited at $355 \mathrm{~nm}$. This wavelength is characteristic of frequency tripled Nd-YAG lasers used in lidars. Fluorescence spectra are expressed in quinine sulphate equivalent units (QSEU); 1000 QSEU correspond to the fluorescence of $1 \mu \mathrm{M}$ quinine sulphate dihydrate in $1 \mathrm{~cm}$ layer of $0.105 \mathrm{~mol} \cdot \mathrm{L}^{-1}$ perchloric acid, excited at $347.5 \mathrm{~nm}$ and emitted at $450 \mathrm{~nm}$, under identical measuring conditions. 


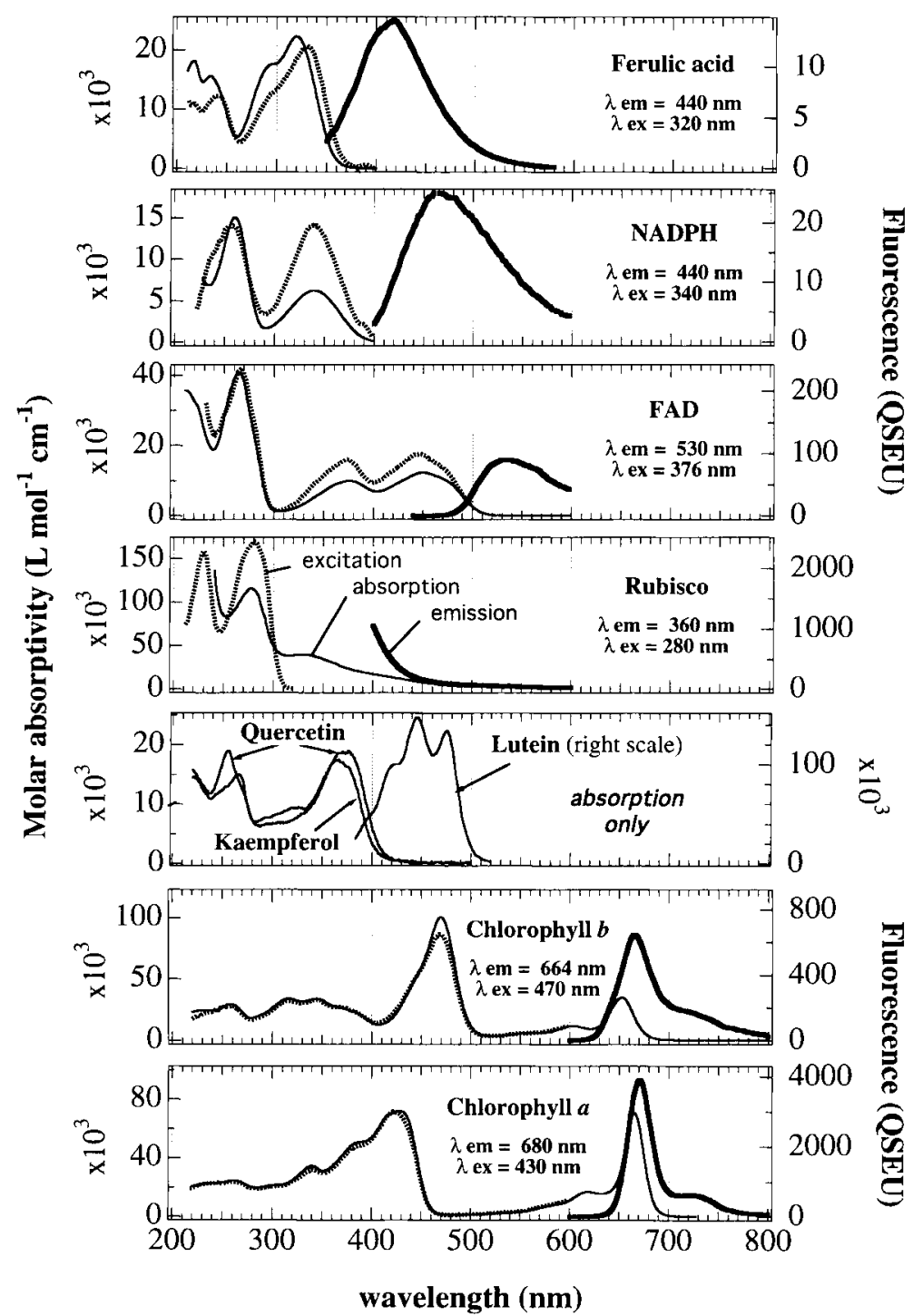

Figure 3. Leaf pigments relevant to UV-excited fluorescence. Absorption and fluorescence characteristics of several important leaf components are presented. In the four top graphs are representatives of $\mathrm{BGF}$ leaf fluorophores, the fifth graph shows strong leaf absorbers which do not fluoresce, and the two bottom graphs show chlorophylls, among which only chlorophyll $a$ will contribute to red fluorescence in vivo. Thin line - absorption, dashed thick line - fluorescence excitation, and full thick line - fluorescence emission. The absorption spectra of ferulic acid in methanol, and all other components, were recorded on the HP5483 spectrophotometer (Hewlett Packard, Les Ulis, France) and expressed as molar absorptivity. The excitation spectrum was recorded on Super-ACO FLU3 set-up with emission wavelength fixed at $440 \mathrm{~nm}$. The emission spectrum was recorded with the excitation wavelength fixed at $320 \mathrm{~nm}$. Fluorescence of $1 \mu \mathrm{M}$ ferulic acid is expressed in quinine sulphate equivalent units (QSEU); 1000 QSEU correspond to the fluorescence of I $\mu \mathrm{M}$ quinine sulphate dihydrate in $1 \mathrm{~cm}$ layer of $0.105 \mathrm{mpl} \cdot \mathrm{L}^{-1}$ perchloric acid, excited at $347.5 \mathrm{~nm}$ and emitted at $450 \mathrm{~nm}$, under identical measuring conditions. NADPH, FAD and Rubisco were in aqueous solutions at $\mathrm{pH}$ 7.9. The flavonols quercetin and kaempferol were in methanol, and the carotenoid lutein in ethanol. Their maximal fluorescence being lower than 0.2 QSEU, only absorbance spectra are presented for these compounds. Chlorophyll $a$ and $b$ were in methanol and their spectra were recorded as for ferulic acid. mum is named near infra-red (NIR) [39] in accordance with the terminology used in passive remote sensing. The blue and green fluorescences, the latter being rarely present as a distinct peak, are also often grouped and treated as blue-green fluorescence (BGF). This BGF has a heterogeneous origin; several leaf fluorophores can fluoresce in this part of the spectrum. It has been rediscovered more recently $[32,35,36]$ and has been far less studied than ChlF. For fine-band detection of fluorescence, using monochromators or narrow-band interference filters, a nomenclature stating the centre wavelength of the filter (which is often the fluorescence maximum) is used: F450 (F440), F530 (F525), F685 (F690) and F735 (F730, F740) (table $I$ ). Even when high resolution fluorescence spectra are discussed, the BF, GF, RF and FRF terminology is more appropriate because the actual maxima of fluorescence emission can change with environmental conditions.

\subsubsection{Chlorophyll fluorescence of leaves}

Chlorophyll $a$ fluorescence is an accurate and non-destructive probe of photosynthetic efficiency 
Table I. Nomenclature of fluorescence variables and signatures.

\begin{tabular}{lll}
\hline $\begin{array}{l}\text { Variable or signature } \\
\text { (abbreviation) or definition* }\end{array}$ & Main fluorophore & Characteristics [references]
\end{tabular}

\section{Chlorophyll fluorescence (ChlF)}

Red fluorescence

(RF) (F685)

Far-red fluorescence

(FRF) (F735)

Variable chlorophyll fluorescence

$\mathrm{F}_{\mathrm{v}} / \mathrm{F}_{\mathrm{m}}=\left(\mathrm{F}_{\mathrm{m}}-\mathrm{F}_{\mathrm{o}}\right) / \mathrm{F}_{\mathrm{m}}$

$\Delta \mathrm{F} / \mathrm{F}_{\mathrm{m}},=\left(\mathrm{F}_{\mathrm{m}}{ }^{\mathrm{o}}-\mathrm{F}_{\mathrm{s}}\right) / \mathrm{F}_{\mathrm{m}}$

$\mathrm{Rfd}=\left(\mathrm{F}_{\mathrm{p}}-\mathrm{F}_{\mathrm{s}}\right) / \mathrm{F}_{\mathrm{s}}$

Chl fluorescence lifetime $(\tau)$

chlorophyll $a$

chlorophyll $a$

chlorophyll $a$ in PSII chlorophyll $a$ in PSII chlorophyll $a$ in PSII chlorophyll $a$ in PSII

\section{Blue-green fluorescence (BGF)}

Blue fluorescence

(BF) (F450)

Green fluorescence

(GF) (F530)

ferulic acid derivatives; other phenylpropanoids; $\mathrm{NAD}(\mathrm{P}) \mathrm{H}$

\section{Fluorescence ratios}

Red/far-red***

(RF/FRF) (F685/F735)

$\mathrm{BGF} / \mathrm{ChlF}$

Blue/red

(BF/RF) (F450/F685)

(BGF/RF or RF/BGF)

Blue/far-red

(BF/FRF)(F450/F735)

(BGF/FRF or FRF/BGF)

Blue/green

(BF/GF) (F450/F530)
Chl in PSII

Chl in PSII and PSI

maximal (photochemical) PSII efficiency[21]**

actual PSII efficiency [56]**

vitality index $[97,101]^{* *}$

proportional to fluorescence yield $[16,118,121]$

heterogeneous; several potential fluorophores [93]; temperature-dependent $[12,13,116]$

mainly epidermal origin $[102,115]$

partially mesophyll origin $[29,150,151]$

chlorophyll $a \quad$ self-reabsorption

species-dependent; sensitive to mineral deficiencies

* For variable ChlF nomenclature see [164].

** These parameters can also be deduced from ChIF lifetime measurements [28].

*** Also known as red fluorescence ratio (RFR) [163].

which can directly or indirectly reflect the impacts of environmental factors on a plant. A complete description of the factors controlling ChlF yield is beyond the scope of this review. ChlF has been reviewed periodically and good recent reviews are available $[10,17,61,78,126,131,141,142]$. For the molecular mechanism of variable chlorophyll fluorescence emission the reviews by Krause and Weis [88] and Dau [44] are recommended.
From figure 3 it can be seen that the absorption spectra of chlorophylls $a$ and $b$ and carotenoids (lutein) extend significantly into the UV region with a large molar absorptivity, especially for chlorophyll $a$. In vivo, chlorophyll $b$ and carotenoids have a role as accessory pigments which transmit the energy they absorb to chlorophyll $a$. Therefore, even under UV-irradiation, the energy of excited $\mathrm{Chl}$ associated with the two pho- 
tochemical complexes, the photosystems I and II, can be used to drive photosynthesis in the chloroplast. Also, a small part (less than $5 \%$ ) of this energy of excitation will be re-emitted by chlorophyll $a$ as fluorescence in the red and far-red region of the spectrum. The intensity of this $U V$ induced ChIF will be very much dependent on the transmittance to UV light of the compounds present in the leaf epidermis (see below).

\subsubsection{Variable chlorophyll fluorescence}

The intensity of ChlF can increase up to six times when a dark-adapted leaf is suddenly illuminated by an actinic light. Upon illumination, fluorescence rises from a minimal level $\left(\mathrm{F}_{0}\right)$ up to a maximum peak $\left(F_{m}\right.$ or $\left.F_{p}\right)$ and then decreases to reach a stationary level $\left(\mathrm{F}_{\mathrm{s}}\right)$. This transient fluorescence induction, known as the Kautsky effect, reflects the photochemical activity of photosystem II (PSII) [88]. At any time, the variation of ChIF is determined by distinct photochemical (qP) and non-photochemical $(\mathrm{qN})$ quenching mechanisms. At the $F_{o}$ level, measured under very weak light, the primary quinone acceptor $\left(Q_{A}\right)$ of PSII is oxidized and the photochemical quenching $\mathrm{qP}$ is maximum. In this case, the absorbed light energy is used for photochemical reaction at the highest efficiency and only a minimal fraction of the absorbed energy is re-emitted as $\mathrm{ChlF}\left(\mathrm{F}_{\mathrm{o}}\right)$. In contrast, upon a dark to light transition, or under a saturating flash, all the $\mathrm{Q}_{\mathrm{A}}$ are temporarily reduced and the PSII photochemical reactions can no longer proceed. At this point, the Fp (or $F_{m}$ ) level is reached and $\mathrm{qP}$ is minimal. Following the $\mathrm{F}_{\mathrm{p}}$ level, fluorescence declines down to a $\mathrm{F}_{\mathrm{S}}$ level owing to the partial re-oxidation of $\mathrm{Q}_{\mathrm{A}}{ }^{-}$(increase of $\mathrm{qP}$ ) and also to the induction of non-photochemical mechanisms $(\mathrm{qN})$. These non-photochemical mechanisms somehow increase the probability of thermal deexcitation of the absorbed light energy and are considered as essential regulatory mechanisms of the photosynthetic control [55]. Hence, thanks to $\mathrm{qN}$, the excess of light energy which cannot be used for photochemical reactions is safely dissipated as heat, thereby protecting the photosynthetic apparatus against deleterious reactions. By the use of modulated fluorometers (PAM) allowing the application of the saturation pulse method [125, 144], the relative importance of $\mathrm{qP}$ and $\mathrm{qN}$ can be routinely determined. However, the pulsed measuring light source has to procure an irradiance lower than $1 \mu \mathrm{mol} \cdot \mathrm{m}^{-2} \cdot \mathrm{s}^{-1}$, in order to be analytical, i.e. to avoid inducing any change in the photochemical efficiency of the chloroplast. The original PAM device used a modulated source of $10 \mathrm{~mW} \cdot \mathrm{m}^{-2}$ $\left(0.06 \mu \mathrm{mol} \cdot \mathrm{m}^{-2} \cdot \mathrm{s}^{-1}\right.$ at $\left.660 \mathrm{~nm}\right)$ integrated intensity [144]. With UV excitation (only $1-40 \%$ is transmitted at 337, depending on the species [45]) 2.5-100 times higher irradiance of the analytical beam can be used owing to epidermal attenuation. Indeed, values as high as $1 \mathrm{~W} \cdot \mathrm{m}^{-2}$ $\left(2.8 \mu \mathrm{mol} \cdot \mathrm{m}^{-2} \cdot \mathrm{s}^{-1}\right)$ were reported not to be actinic when nitrogen lasers were used; there were no changes in ChlF yield induced by the analytical beam $[26,155]$.

In leaves at room temperature (above zero), it is largely considered that most of fluorescence at 685 and $735 \mathrm{~nm}$ emanates from PSII [88], with some minor PSI fluorescence in the $710-720 \mathrm{~nm}$ region [17, 88]. However, Pfündel [127] has recently estimated that in intact leaves at $\mathrm{F}_{0}$, when all photosystems are in an open state (i.e. minimal ChlF level under very low light intensity), the PSI contribution to the total ChlF at a wavelength longer than $700 \mathrm{~nm}$ accounted for about 30 and $50 \%$ in C3 and $\mathrm{C} 4$ plants, respectively [127]. This is in line with previous data on the effect of non-photochemical quenching of ChlF at $720 \mathrm{~nm}$ [57]. At this wavelength, $30 \%$ of ChlF in $\mathrm{C} 3$ plants and $50 \%$ of ChlF in $\mathrm{C} 4$ plants were not affected by non-photochemical quenching at the $\mathrm{F}_{0}$ level. Also, we found for bean leaves excited at $340 \mathrm{~nm}$ that the non-variable part of F730 (not affected by the reduction of $\mathrm{Q}_{\mathrm{A}}^{-}$) represents $55 \%$ at the $\mathrm{F}_{\mathrm{o}}$, and $10 \%$ at the $\mathrm{F}_{\mathrm{m}}$ level.

\subsubsection{Blue-green fluorescence of leaves}

There are two fundamental differences between leaf BGF and ChlF. In contrast to ChIF, BGF is independent of ambient light level and is practically constant on a short time scale (minutes) but can vary over longer time periods (hours and days). Second, whereas ChlF emanates only from chlorophyll $a$, several compounds can contribute to the emission of blue-green fluorescence (BGF) upon 
UV excitation. Ferulic acid, a hydroxycinnamic acid that is covalently linked by ester bounds to the polysaccharides of cell walls in leaf epidermis and leaf veins [69] is thought to be responsible for most of the leaf BGF $[69,102,115]$. Still, other products of the plant secondary metabolism can significantly contribute to this 'constant' BGF. In the extensive review of Wolfbeis [171] the following natural compounds, known to be present in leaves, are cited to emit fluorescence in the bluegreen part of the spectrum when excited by UV radiation: hydroxycinnamic acids (caffeic, ferulic, sinapic), chromones, stilbenes (resveratrol), coumarins (umbelliferone, esculetin, scopoletin), furocumarins (psoralen), flavonols, flavones (except 5-hydroxyflavones), isoflavones, flavanones, chalcones, aurones, phenolic acids (salicylic, gentisic, ellagic), nicotinamides (NADH, NADPH), flavins (FMN, FAD, riboflavin), other coenzymes (pyridoxal-5'-phosphate), pterines (folic acid, dihydrofolate), polyenes (phytofluen), quinones (phyllohydroquinone), alkaloids (berberine, quinine, lysergic acid), and degradation products (kynurenine, polyadenylic acid). The phenolic acids, coumarins, chromones, stilbenes, flavonoids can all be free, esterified or polymerized in the cell (lignans, tannins, lignins). These products are biosynthetically related (coming from the shikimate pathway) and are generically named plant phenolics (polyphenols) or sometimes phenylpropanoids after the structure of the main intermediate, cinnamic acid [50].

Even when present in a leaf of a particular plant species, not all of the mentioned compounds will contribute to leaf fluorescence. Their contribution will depend on: localization of the fluorophore in the leaf, fluorophore concentration, absorption (excitation) spectrum, molar absorptivity, emission spectrum and fluorescence quantum yield. The fluorophore's environment, including temperature, viscosity, spatial constraints, $\mathrm{pH}$, polarity and presence of quenchers, such as heavy metals and oxygen, will also influence the spectral characteristics and yield. The importance of a fluorophore for fluorosensing will depend on its spectral characteristics compared to the fluorosensor characteristics.
Spectral characteristics of most prominent and omnipresent fluorophores and absorbers in a typical leaf that can influence BGF are presented in figure 3. Ferulic acid was chosen as a representative of the phenolic group of compounds known to be present in leaves in substantial amounts and to be fluorescent. Emission spectra of blue-fluorescing fluorophores are very wide (FWHM of $82 \mathrm{~nm}$ for ferulic acid and $112 \mathrm{~nm}$ for NADPH (figure 3)); therefore, it is difficult to identify a fluorophore by its emission spectrum alone. Yet, ferulic acid has an emission maximum at $420 \mathrm{~nm}$, and NAD(P)H $40 \mathrm{~nm}$ further towards the red, at $460 \mathrm{~nm}$.

Flavins are both absorbers in the UV-A and blue part of the spectrum and good fluorophores in the green (figure 3). It is worth noting that, unlike NADPH, it is the oxidized form of flavin nucleotides that fluoresce. Still, the contribution of FAD and FMN in vivo is minimized by their association with proteins (enzymes) which quench their fluorescence [167].

The major protein of the leaf, D-ribulose-1,5bisphosphatecarboxylase/oxygenase - Rubisco [72], has a very strong fluorescence when excited in the UV-B owing to the amino-acid tryptophan. Its fluorescence can contribute substantially above $400 \mathrm{~nm}$ (figure 3). When exciting the leaf with UVA, the tryptophan contribution is negligible, but still, as can be seen from figure 3, isolated Rubisco also absorbs around $340 \mathrm{~nm}$. The origin of this absorption, and the associated fluorescence, is not clear and can originate from degradation products [22] or even from fixed pyridine nucleotides.

The two major flavonols of leaves, quercetin and kaempferol [133], are present in the vacuole of epidermal cells [68] (as glycosides) or in cuticular wax (as aglycones) [172]. They are shown here (figure 3) as aglycones, and have two absorption peaks around 260 and $370 \mathrm{~nm}$, with a minimum around $300-320 \mathrm{~nm}$ where the hydroxycinnamic acids absorb. Thus, flavonols and hydroxycinnamic acids efficiently protect the leaf by covering the whole UV range and absorbing most of solar UV radiation. In addition, flavonols may considerably influence the intensity of the UV-induced fluorescence, especially ChlF which emanates from the 
mesophyll. BGF will also be affected but to a much smaller degree because it is emitted mostly from the surface of the leaf. It is important to note that the flavonol concentration of a leaf varies considerably during development $[46,83]$, is increased under high light [90] and in the presence of UV radiation [132]. Changes in flavonol concentrations that follow the diurnal light intensity variation (maximal concentration of flavonols at noon) have also been reported [166].

In general, there are two types of information that can be obtained from BGF. The first type of $\mathrm{BGF}$ is related to the above-mentioned plant phenolic and flavonoid compounds bound to the walls or found in the vacuoles of epidermal cells. This BGF can be considered as static, dependent of cell constituents and leaf structure, and can be measured with most fluorimeters including lidars. The second type of BGF, which is more related to plant biochemistry and especially photosynthesis, needs very sensitive fluorimeters of the PAM type [26, 143]. It concerns the monitoring of the variation of the concentration and redox state of pyridine nucleotides (NADH and NADPH) which are good BGF fluorophores, but due to their localization in the mesophyll cells, and especially for NADPH, in chloroplasts, they are less accessible to UV excitation and their fluorescence is re-absorbed by photosynthetic pigments. This limits pyridine nucleotide contribution to BGF in intact leaves to less than $10 \%$ in most cases (see below). NADPHdependent BGF can be changed by applying actinic light which drives photosynthesis, as opposed to 'constant' leaf BGF [26]. This lightinduced variable $B G F$ can therefore be used to detect, or even quantify, redox changes in the chloroplast. It can be measured even in leaves with very sensitive fluorimeters [29], and can be compared to variable ChlF because it depends, as does $\mathrm{ChlF}$, on the redox state of the stroma.

\subsection{Fluorescence ratios}

Since BGF and ChlF have distinct origins, they can change independently in response to different physiological and environmental factors. These changes are more conveniently described in terms of variations of the fluorescence ratios rather than absolute fluorescence changes, which are strongly affected by external factors such as distance, atmospheric scattering and leaf geometry and movements. The fluorescence ratios currently used in fluorosensing are: a) red to far-red (RF/FRF), b) blue to $\mathrm{ChlF}$ (BF/RF and $\mathrm{BF} / \mathrm{FRF}$ ), and c) blue to green $(\mathrm{BF} / \mathrm{GF})$ ratios (table I).

In order to exploit these fluorescence ratios or identify alternative ratios as diagnosis for specific physiological states or environmental stresses, it is important first to consider the intrinsic leaf properties and molecular mechanisms that can modify the BGF and ChlF emissions. Alteration of the UVinduced fluorescence spectra by physiological and environmental factors is the symptom of their primary effect on one or more intrinsic leaf properties or molecular mechanisms therein: 1) contents of secondary metabolites in leaf epidermis, namely ferulic acid and UV-absorbing flavonoids; 2) leaf photosynthetic pigment content; 3) leaf temperature; 4) photochemical and non-photochemical quenching of ChlF; and 5) apoplastic and vacuolar $\mathrm{pH}$. The wavelength of the exciting light also plays an important role. An adequate understanding of these different factors and their impacts on UVinduced leaf fluorescence is essential in order to assess reliably the physiological status of plants from their fluorescence signatures.

\subsubsection{The $R F / F R F$ ratio}

The RF/FRF ratio (F685/F735) was the first signature introduced by Lichtenthaler et al. [97]. It depends on the chlorophyll content of the leaf and on leaf anatomy. Owing to the selective re-absorption of red relative to far-red fluorescence by $\mathrm{Chl}$ molecules [58, 130], there is an inverse curvilinear relationship observed in many plant species between the F690/F740 ratio and the leaf $\mathrm{Chl}$ content [58] (the wavelengths 690 and $740 \mathrm{~nm}$ were used for the RF/FRF ratio in this particular work). The F690/F740 ratio is largely affected by changes in Chl content at values lower than $250 \mathrm{mg} \cdot \mathrm{m}^{-2}$, i.e. in pale leaves. Unfortunately, the sensitivity of the F690/F740 ratio decreases drastically at Chl content higher than $300 \mathrm{mg} \cdot \mathrm{m}^{-2}$ where in practice 
no differences can be detected by this fluorescence ratio [58]. Nevertheless, the F690/F740 ratio was useful to monitor the degradation of chlorophyll, carotenoids and the photosynthetic apparatus in leaves of Xerophyta scabrida during slow desiccation [40]. It must be mentioned, however, that most environmental stresses are expected to only slowly modify Chl concentration.

The RF/FRF ratio can also show changes of small amplitude at constant $\mathrm{Chl}$ content. Changes in the RF/FRF ratio, have been detected during the diurnal cycle (in the range $0.75-1.15$ ) $[2,163]$ and under temperature stress [1,2]. The dependence of the signature on irradiance indicates that these changes are due to a change in the level of nonphotochemical quenching of ChlF. Therefore, it belong to a category of variable ChIF signatures. Some authors use the FRF/RF ratio, which is symmetrical to RF/FRF, having the same origin and dependence [111].

\subsubsection{The $\mathrm{BF} / \mathrm{ChlF}$ ratios}

The BF/ChIF ratios (F450/F685 and F450/F735) are the most sensitive signature in UV-induced fluorosensing. They will increase following the accumulation of leaf secondary metabolites in the epidermis that can emit blue fluorescence such as ferulic acid. The UV-induced fluorescence emission can be modified by other hydroxycinnamic acids (namely caffeic, $p$-coumaric and cinnamic acids) bound to the cell walls as well as other phenolic compounds and flavonoids in the vacuole of epidermis cells. These compounds seem to contribute very little to the BGF although they strongly absorb UV-light [82, 102, 115] Their concentrations can significantly increase after exposure to elevated UV-B levels, resulting in a natural photoprotective screening against the deleterious effects of UV irradiation [23]. Large differences in their concentrations are also observed between outdoorand greenhouse-grown plants $[105,106]$. The presence of compounds with high UV-B absorptivities in the epidermis therefore attenuates the UV excitation of Chl molecules in mesophyll cells, and, consequently, decreases the intensity of UVinduced Chl fluorescence $[13,26,82,145,152]$; as a result, the $\mathrm{BGF} / \mathrm{ChlF}$ ratio increases [20]. A decrease in epidermal transmittance to UV will affect ChlF more than BGF, which comes mostly from the surface of the leaf.

Similarly to the leaf secondary metabolites in the epidermis, the various leaf pigments absorbing in the visible region markedly modulate the shape of the fluorescence emission spectrum in two different ways. First, since red and far-red fluorescence emanates exclusively from chlorophyll $a$, its intensity is directly related to the chlorophyll $a$ content in the upper layers of the leaf. Second, the leaf pigments absorbing visible light can re-absorb a large part of the fluorescence emission. Indeed, there is a strong overlap between the leaf absorption and the fluorescence spectrum, especially in the blue region $(380-500 \mathrm{~nm})$ where both chlorophyll and carotenoids absorb and also in the red region, where only chlorophyll absorbs (figure 3 ). Very little re-absorption of emitted fluorescence occurs in the far-red region. Therefore, the fluorescence emission spectra measured from leaves represent the difference between the intensity of actually emitted fluorescence and its re-absorption by the leaf pigments $[20,58,130]$. For example, wheat leaves either etiolated in darkness or bleached with herbicides exhibited much stronger BGF and larger F440/F690 ratio than green leaves as a result of a lower re-absorption of emitted fluorescence by photosynthetic pigments $[150,154]$. Also, a large increase in BGF was indicative of the progressive loss of photosynthetic pigments in sugar beet leaves affected by iron deficiency [114].

The BGF/ChlF ratios are also strongly dependent on the wavelength of the excitation light owing to the markedly different excitation spectra of the blue-green fluorophores and chlorophyll $a$ molecules (figure 3). It appears that UV excitation at $355 \mathrm{~nm}$ is a good compromise to simultaneously excite both BGF and ChIF (figure 4). Excitation at higher wavelengths will increase ChlF yield, and excitation at a shorter wavelength will favour BGF [20, 145, 152] (figure 4).

BGF excitation spectra can show two excitation peaks at 330 and $250 \mathrm{~nm}$, whose relative importance seems to be dependent on species or environmental conditions. In sugar beet leaves, the $330 \mathrm{~nm}$ 


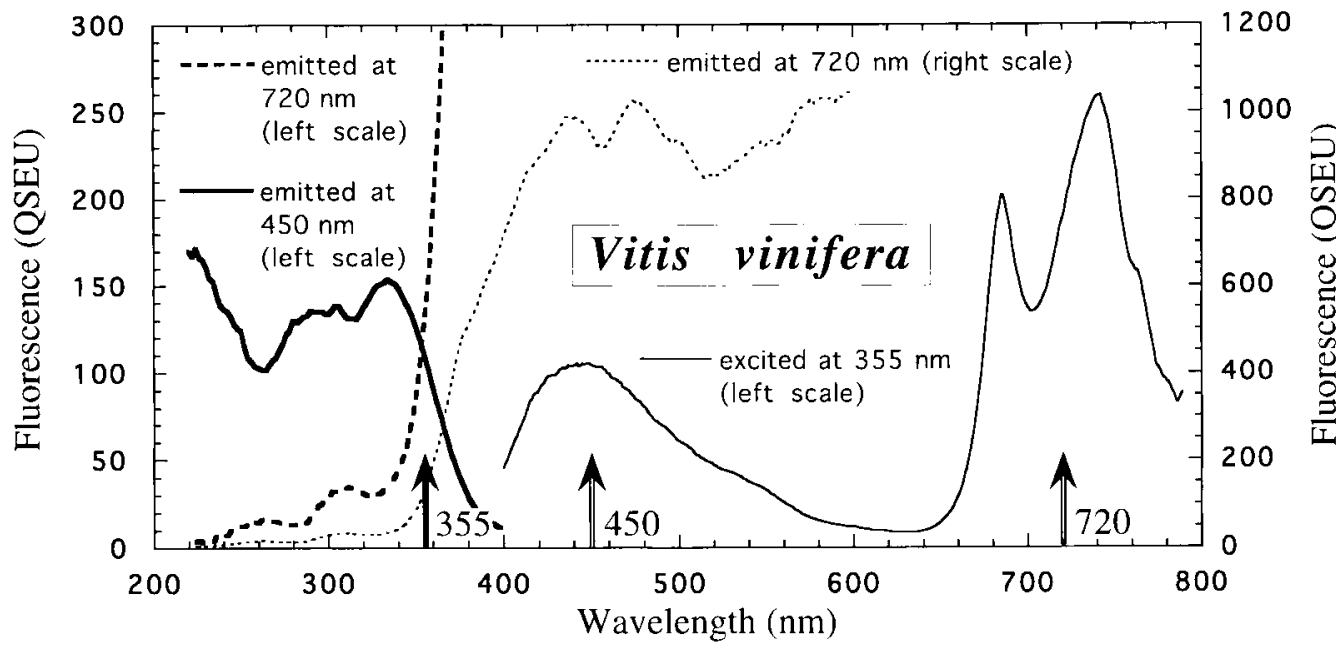

Figure 4. Excitation and emission fluorescence spectra of a grapevine leaf (Vitis vinifera cv. Cabernet-Sauvignon). Fluorescence excitation and emission spectra of the adaxial sides of the leaf were recorded on the FLU3 set-up of the SA4 line of Super-ACO storage ring at LURE in Orsay. Fixed excitation $(355 \mathrm{~nm})$ and emission $(450$ and $720 \mathrm{~nm})$ wavelength are indicated by arrows, for the emission and excitation spectra, respectively. Note that the excitation spectrum of fluorescence emitted at $720 \mathrm{~nm}$, which emanates solely from chlorophyll $a$, was plotted twice.

peak was predominant [115], whereas the opposite was observed in beech leaves [145], suggesting that the relative importance of these two excitation maxima is strongly dependent on leaf composition.

ChlF excitation spectra depends mainly on the plant growing conditions, with a drastic decrease in UV-excitation in outdoor-grown plants compared to phytochamber-grown plants [152], and in sun leaves compared to shade-grown leaves [145]. This is due to a decrease in epidermal transmission and can be exploited to measure the transmittance of the epidermis using ChlF $[8,146]$.

Finally, the use of BF/FRF (F450/F735) ratio is preferable compared to the $\mathrm{BF} / \mathrm{FR}$ ratio because F735 minimizes fluorescence re-absorption by photosynthetic pigments, and the photochemical (qP) and non-photochemical quenching (qN) of ChlF are smaller at $735 \mathrm{~nm}$.

\subsubsection{The $\mathrm{BF} / \mathrm{GF}$ ratio}

The BF/GF ratio depends on the emission spectrum of the main $\mathrm{BF}$ fluorophore and on the contribution of green emitting fluorophores (flavins and flavonoids) located either in leaf epidermis or in leaf mesophyll (see later for the estimation of mesophyll GF relative to leaf GF in section 2.4.2.). An important proportion of the green fluorescent band will come from fluorophores which have a maximum in the blue, because of the very large width of their emission spectra (figure 3). For hydroxycinnamic acids it will be from 15 to $20 \%$ depending on the acid (ferulic $15 \%$, caffeic $20 \%$ ) [93, 115$]$.

When present in the epidermis, anthocyanins can also re-absorb GF and increase the BF/GF ratio. Anthocyanins, which have strong absorptivities in the green $(530-550 \mathrm{~nm})$ of up to 40000 $\left(\mathrm{L} \cdot \mathrm{mol}^{-1} \cdot \mathrm{cm}^{-1}\right)$ [133], are commonly described as stress markers in vegetative tissues [149] because they accumulate as a result of cold temperature, dehydration, sugar accumulation and phosphate deficiency. All these strains and stresses can therefore potentially influence the $\mathrm{BF} / \mathrm{GF}$ and $\mathrm{BGF} / \mathrm{ChlF}$ ratios.

The apoplastic pH could be another factor that could affect the BF/GF ratio. Early studies on UVfluorescence microscopy of leaf transverse sections of Italian ryegrass (Lolium multifolium L.) showed that ferulic acids esterified to cell wall polysaccha- 
rides (feruloyl esters) fluoresced blue at $\mathrm{pH} 5.4$ and completely green at $\mathrm{pH} 10.0[69,76]$ (see also figure 5). A similar $\mathrm{pH}$ effect was also observed with feruloylated polysaccharides purified by thin-layer chromatography from Lolium temulentum cell walls. This shift from blue to green fluorescence was shown to be reversible [69]. However, neither the $\mathrm{pK}_{\mathrm{a}}$ of the esterified ferulic molecule responsible for the blue to green fluorescence transition nor the physiological significance of this transition have yet been determined.

The above considerations could be relevant for the interpretation of the blue to green fluorescence ratio. It was recently reported that a large increase of the green fluorescence band F520 relative to the F440 band can occur under various long-term stress conditions [20, 114]. This increase was suggested to result from the accumulation of green fluorescing compounds. However, increase in apoplastic $\mathrm{pH}$ might be an alternate hypothesis worth verifying.

\subsubsection{Limitations of fluorescence ratios}

The main drawback of fluorescence ratios is that they depend on two variables that can vary independently, precluding unambiguous interpretation of the change of the ratio. BGF seems more stable on the short-term scale (hours) and therefore could be used as a reference for variable ChIF under unstressed conditions. Still, a neutral 'isosbestic' wavelength for fluorescence should be found and tested (possibly $630 \mathrm{~nm}$ ), which would avoid double variable. Comparisons among different species show an apparent isosbestic point between 620 and $640 \mathrm{~nm}[35,93,102,151,152]$.

An important problem would still remain for the use of fluorescence ratios in remote sensing. The presence of a background (stray light) signal will affect the value of the ratio, even if it stays constant along the spectrum (which in addition is not always the case, depending on the origin of the stray light). Again, the use of a pseudo-isosbestic value around $630 \mathrm{~nm}$, which would be subtracted from the fluorescence bands before the calculation of the ratio, could be the solution to the problem of background.

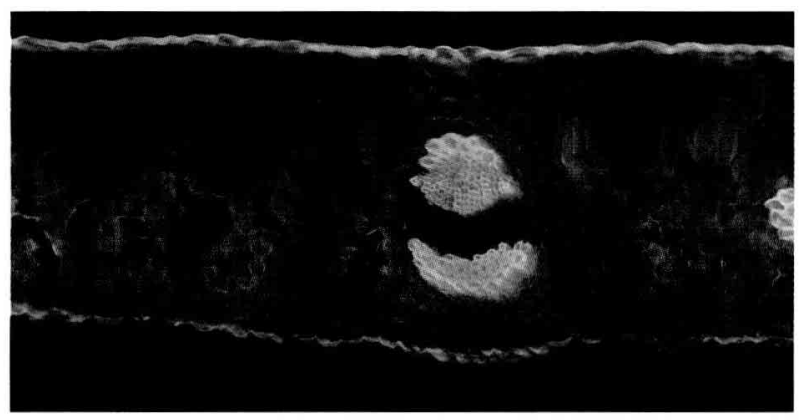

Figure 5. UV-excited fluorescence of a transverse section of a leaf of Daphniphyllum macropodum Miquel. The leaf was cut by hand and the fluorescence of a transverse section photographed on an epi-fluorescence microscope (Axiophot, Zeiss, Jena, Germany). The filter combination used (XF02, Omega, Brattleboro, USA) allowed a wide band UV excitation (330WB80 interference filter) and total fluorescence emission in the visible spectrum above $400 \mathrm{~nm}$ (dichroic filter 400DCLPO2, blocking filter 400EFLP). Photograph courtesy of Dr. Sonja Yakovlev, Orsay, France. Magnification $\times 75$.

An alternative to fluorescence ratios was used in $[135,158]$. They showed seasonal variations, from June to December, of tree leaf fluorescence, and used circular graphs (radar graphs) to present variations of all four fluorescence bands simultaneously.

\subsection{Fluorescence lifetime}

Another alternative to fluorescence ratios is the use of fluorescence lifetime. This parameter, being a measure of time, is inherently insensitive to atmospheric perturbations. Presently the major limitation for its use as a signature is a more complex, and more expensive, electronic system used for measurements of nanosecond events, which is the time domain of fluorescence of natural organic fluorophores.

There is not much information in the literature on stress-induced changes in ChlF lifetimes in intact leaves, and even less with the use of UV excitation. Schneckenburger and Frenz [140] reported increases in ChlF lifetimes in spruce and pine needles after exposition to high $\mathrm{O}_{3}$ doses. Heat stress in barley leaves [15] and Fe deficiency in sugar beet leaves [113] also increased the ChlF 
lifetime. Dark-adapted, water-stressed leaves had similar ChlF lifetimes than controls; however, once illuminated water-stressed leaves showed decreases in ChlF lifetime when compared to the controls $[28,139]$. Most of these studies have been performed under laboratory or greenhouse conditions and only some of them used $\tau$-LIDAR devices [28, 147]. These special lidars use very short laser pulses (35 ps) and very rapid detectors and electronics (streak camera [147], or photomultiplier tube [28]). This permits a comparison of the form of the emitted fluorescence with the excitation pulse and allows the mean fluorescence lifetime of leaves in the nano-second time domain to deduced.

Concerning BGF lifetimes, there is even less information than for ChIF lifetimes. There is one report [114] showing that Fe deficiency increases the contribution of the BGF slow kinetic component (4.2-4.6 ns) owing to an accumulation of flavins in the mesophyll of Fe-deficient sugar beet leaves. However, this work was carried out with mesophyll pieces (avoiding the BGF contribution of the epidermis) and the BGF lifetime change did not seem to be large enough to be detected at distance. Further work is required to determine the pertinence of fluorescence lifetime as a signature for remote sensing in field conditions.

\subsection{Importance of leaf structures for UV-induced fluorescence}

\subsubsection{Leaf anatomy}

Fluorescence imaging has shown that BGF emanates primarily from the main and lateral vascular bundles (veins), whereas the ChlF predominantly comes from the interveinal areas (for tobacco see $[20,73,81,91,98]$ ) (figures 5 and 6). This can be related to the finding of Hartley and Harris who reported that, in all of the 251 species from 150 families of dicots they surveyed, the lignified cell walls of sclerenchyma fibres and xylem vessels fluoresced blue [71]. As seen from figures 5 and 6 , sclerenchyma bands above the vascular bundle are responsible for BGF. The absence of $\mathrm{Chl}$ in sclerenchyma cells precludes the screening and re-

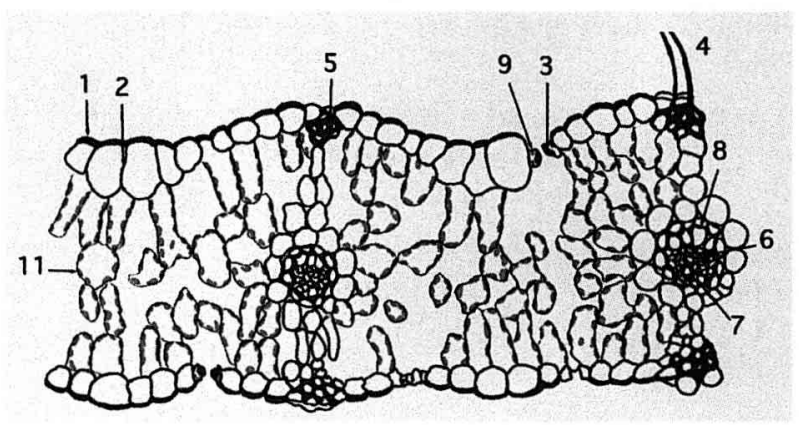

Figure 6. Drawing of a transverse section through a typical leaf of a monocotyledonous Gramineae (Triticum aestivum L.). This schematic drawing is based on the anatomy of monocotyledonous leaves described in [54]. The structures that fluoresce blue-green light under UV excitation are colored blue, and those fluorescing red light (chloroplasts) are colored red. Fluorescence is based on data from $[69,83,154]$. Numbers relate to structures listed in table II. Note the presence on the figure of two vascular bundles, a trichome, and bulliform epidermal cells. Magnification $\times 150$ ).

absorption by photosynthetic pigments of this 'vein' BGF.

Still, the cuticle is the first structure of a leaf to be illuminated, and therefore its contribution to BGF will be important if it contains BGF fluorophores. Indeed, cuticles of all dicotyledonous (251) and monocotyledonous (104) species examined by Hartley and Harris fluoresced when excited by UV-A radiation [70, 71]. The latest microscopy studies related to BGF fluorosensing $[137,154]$ show that the cuticle has indeed the strongest BGF (figure 5). There are also claims that $\mathrm{BF}$ comes from the epicuticular wax because BF can be transferred from the leaf to a quartz lamina using organic solvents $[12,13]$. Indeed, Bongi and coworkers have shown that by dipping leaves in acetone the epicuticular wax and the components it contains are removed (dissolved) without otherwise disrupting leaf structure. After evaporating the solvent from the obtained extract, the remaining components show a BF comparable to the mother leaf $[12,13]$.

The other compounds responsible for the fluorescence in the different leaf structures are listed in table II. It can be seen that the chloroplasts are the 
Table II. Leaf anatomical structures which emit strong fluorescence under UV-A excitation (based on references [69, $83,154])$.

\begin{tabular}{|c|c|c|}
\hline & Compound & $\begin{array}{c}\text { Number } \\
\text { on figures } 6 \text { and } 7\end{array}$ \\
\hline
\end{tabular}

Blue-green fluorescence

\section{Epidermis}

Cuticle

Epidermal cell walls

Reinforced cell walls of stomatal guard cells

hairs (trichomes)

Cell walls of sclerenchyma bands (monocots)

Vascular bundle

Cell walls of xylem vessels

Phloem cell walls (sieve-tubes)

Cell walls of sclerenchyma sheaths

around vascular bundles

Cell walls of bundle-sheath cells

(C4 monocots)

\section{Red fluorescence}

Epidermis

Guard cell chloroplasts

Mesophyll

Chloroplasts in palisade and spongy parenchyma cells epicuticular wax with dissolved flavonoid aglycones

cutin with esterified hydroxycinnamic acids

esterified hydroxycinnamic acids (ferulic acid)

esterified hydroxycinnamic acids

esterified hydroxycinnamic acids?

esterified hydroxycinnamic acids

lignin

esterified hydroxycinnamic acids

lignin; esterified hydroxycinnamic acids

1

2

3

4

5

suberin with esterified hydroxycinnamic acids chlorophyll a 9

chlorophyll $a$

chlorophyll $a$
10

11 only structures fluorescing red light. The real panchromatic view of UV-induced fluorescence can be seen in the photograph of the transection of an evergreen dicot (Daphniphyllum macropodum Miquel.) (figure 5). This photograph illustrates the variety of fluoresced colours under UV excitation, whose exact assignment merits further research efforts.

The presence of a thicker epidermis on the adaxial side for bifacial leaves of dicots (figures 5 and 7) can explain why in general the UV-induced fluorescence emission of the upper leaf side (adaxial) is lower than that of the lower leaf side (abaxial) for the blue, green and red fluorescence [103] (figure 8). This is the consequence of a larger transmittance of abaxial than adaxial epidermis for UV-A radiation because of a larger proportion of flavonoids in adaxial than abaxial epidermis [161, $162,170]$. In addition, according to Buschmann and Lichtenthaler [20], the presence of densely packed palisade cells in the adaxial side of the leaf

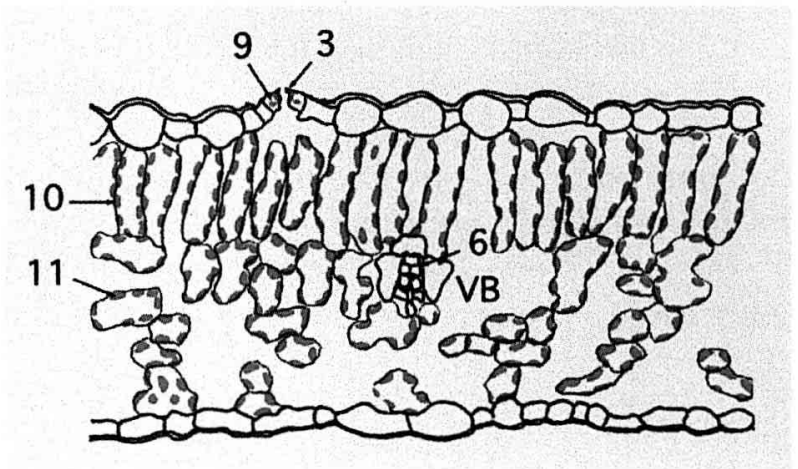

Figure 7. Drawing of a transverse section through an interveinal region of a typical dicotyledonous leaf (Nicotiana tabacum L.) showing the fluorescent structures. This schematic drawing is based on the anatomy of dicotyledonous leaves described in [54] and personal experience. The structures that fluoresce blue-green light under UV excitation are coloured blue, and those fluorescing red light (chloroplasts) are coloured red. Numbers relate to structures listed in table II. Note the presence on this figure of a single small vascular bundle VB, situated at the interface between the palisade and spongy parenchyma. A pair of guard cells is forming a stoma in the adaxial epidermis. Magnification $\times 190$. 
increases the re-absorption by chlorophyll $a$ of the blue and red fluorescence induced from this side, which leads to a decrease in the $B / F R$ and $R / F R$ fluorescence ratios.

\subsubsection{Estimation of the contribution of mesophyll fluorescence to leaf BGF in vein-free leaf parts}

We mentioned already that the epidermis is screening and protecting the mesophyll from UV radiation. This effect is very much dependent on the irradiance under which the leaf has grown [90] because flavonoids tend to accumulate in the vacuoles of epidermal cells [68] and in the cuticle [172], and the overall thickness of the adaxial epidermis increases under strong light [9] (see also the effect of UV-radiation on leaves, 4.2.). All this will influence the part of BGF coming from the mesophyll.

By comparing ChlF from an intact leaf with mesophyll (leaf without epidermis) we can estimate the proportion of UV radiation that will reach the mesophyll in an intact leaf. In other words, we can use chlorophyll fluorescence as an internal probe to estimate the transmittance of the epidermis in the UV $[8,26]$ : proportion of UV radiation reaching the mesophyll = leaf RF/mesophyll RF

Once we know the proportion of UV light reaching the mesophyll, where it induces $\mathrm{BF}$, we can calculate what proportion of the total BF of an intact leaf this BF represents:

(mesophyll BF)

mesophyll contribution to leaf BF

$$
=\frac{\text { (leaf RF/mesophyll RF) }}{\text { leaf BF }}
$$

$=($ mesophyll BF) (leaf RF)/(leaf BF) (mesophyll RF)

The calculation is the same for GF. From table $I I I$ it can be seen that BGF from mesophyll will appear more in the GF band than in the BF band of the intact leaf, as first suggested by Lang et al. [92] and confirmed by time-resolved studies [30]. This is the consequence of the spectral characteristics of epidermal fluorophores, which have a maximum of fluorescence near $420 \mathrm{~nm}[30,92]$, and the consequence of a very strong re-absorption of mesophyll BGF by the photosynthetic pigments (figure 3 and 9). These are the two main reasons why Cerovic et al. [29] proposed to follow NAD(P)H fluorescence, which comes from the mesophyll, in the green

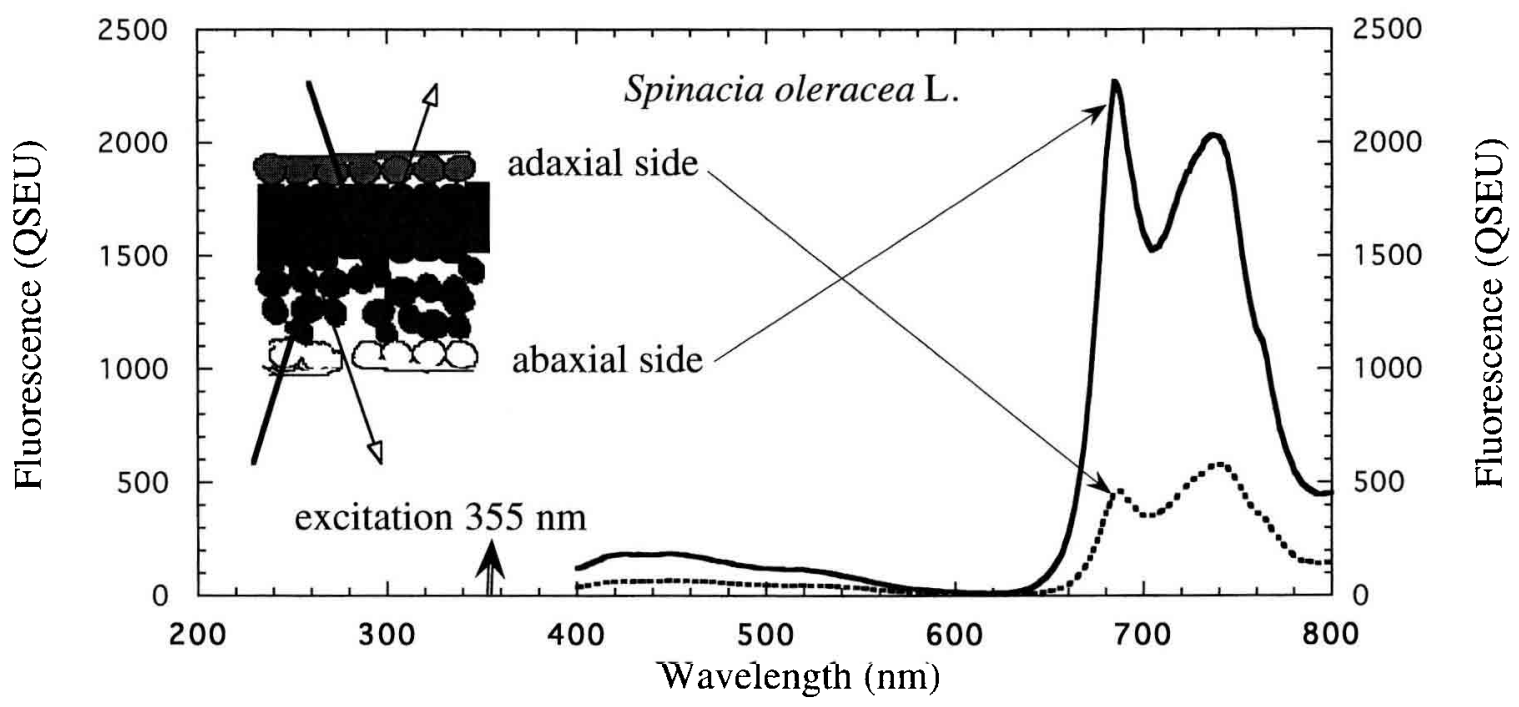

Figure 8. UV-excited emission fluorescence spectrum depends on leaf structure. Fluorescence emission spectra of adaxial and abaxial sides of a young spinach leaf (Spinacia oleracea L.) were recorded on the FLU3 set-up of the SA4 line of Super-ACO storage ring at LURE in Orsay. They were excited at $355 \mathrm{~nm}$. This wavelength is characteristic of frequency tripled Nd-YAG lasers used in lidars. 
Table III. Estimation of the contribution of mesophyll BF and GF to leaf BGF, using ChlF as an internal probe for epidermal transmittance. Fluorescence intensities are presented in relative units normalized to 100 for each band and species because of the variety of sources; references indicated in brackets.

\begin{tabular}{lcccccccc}
\hline & \multicolumn{2}{c}{$\begin{array}{c}\text { Red emission } \\
\text { (F690) }\end{array}$} & $\begin{array}{c}\text { Blue emission } \\
(\mathrm{F} 440)\end{array}$ & $\begin{array}{c}\text { Contri- } \\
\text { bution }\end{array}$ & $\begin{array}{c}\text { Green emission } \\
\text { (F520) }\end{array}$ & $\begin{array}{c}\text { Contri- } \\
\text { bution }\end{array}$ \\
\cline { 2 - 9 } Species & Leaf & Mesophyll & Leaf & Mesophyll & $(\%)$ & Leaf & Mesophyll & $(\%)$ \\
\hline Xerosycios decaryi [20] & 6 & 100 & 100 & 62 & $\mathbf{4}$ & 100 & 200 & $\mathbf{1 2}$ \\
Beta vulgaris L. [30] & 12 & 100 & 100 & 59 & $\mathbf{7}$ & 100 & 128 & $\mathbf{1 5}$ \\
Silene dioica L. [13] & $20^{*}$ & $100^{*}$ & 100 & 33 & 7 & - & - & - \\
Spinacia oleracea L. [26] & 25 & 100 & 100 & 77 & $\mathbf{1 9}$ & - & - & - \\
Pisum sativum L. & 20 & 100 & 100 & 205 & $\mathbf{4 1}$ & - & - & - \\
\hline
\end{tabular}

* Calculated from epidermal transmittance.

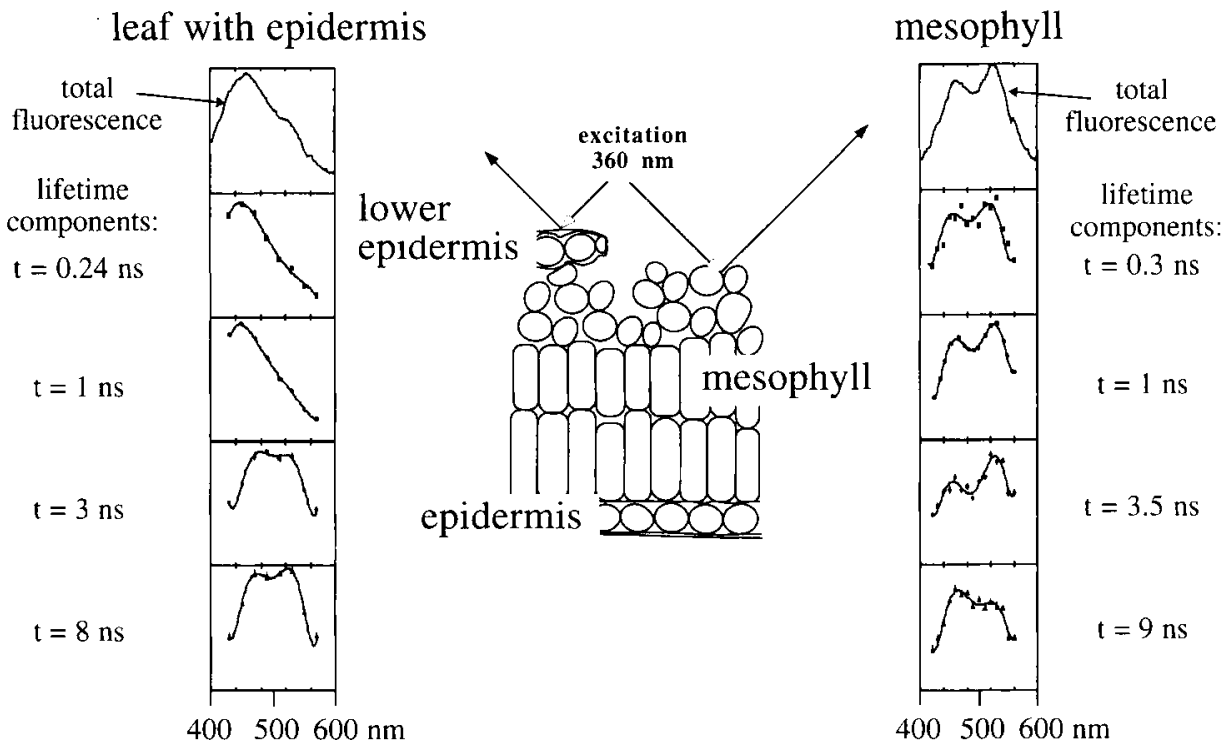

Figure 9. Decay-associated BGF spectra of an intact leaf and mesophyll (abaxial side) of sugar beet plants (Beta vulgaris L.) (after [30]). Time-correlated single-photon-counting measurements of fluorescence decays were performed on the Super-ACO FLU3 set-up in Orsay (France). Measurements were performed in the front-face configuration with an angle of incidence of $30^{\circ}$ to the sample window and detection at $90^{\circ}$ to minimize the contribution of reflected light. Discs of leaves, or leaves from which the lower epidermis was striped away, were cut and enclosed in a home-made thermostated chamber, the illuminated face pressed against a quartz window. For each wavelength, the fluorescence decay curve was decomposed into four lifetime components by iterative deconvolution. Then, a global fit was performed to all decays in a spectrum simultaneously to obtain the presented decay-associated spectra.

band instead of the blue band, in which NAD(P)H in solution has its fluorescence maximum (figure $3)$.

Mesophyll contribution to fluorescence will depend also on leaf temperature [116]. For the BF of sugar beet leaves, calculations described in table
III gave a contribution of 8 and $4 \%$ at 33 and $3{ }^{\circ} \mathrm{C}$, respectively. For GF, the contribution was 11 and $8 \%$ at 33 and $3{ }^{\circ} \mathrm{C}$, respectively, indicating that higher temperatures favour contribution from the mesophyll by decreasing preferentially BGF from the surface [116]. 
Another attempt to estimate the proportion of green and blue emitting fluorophores in the green band was to decompose the emission spectra by fitting elementary Gaussian curves [156]. However, this approach is questionable owing to the effect of re-absorption.

In summary: 1) UV-induced BGF originates mainly from the epidermal layer; 2) the proportion of mesophyll fluorescence to total BGF is higher in the GF than in the BF band; 3) in a whole leaf, veins contribute mostly to $B G F$ and vein-free leaf regions to $\mathrm{ChlF}$; 4) the leaf secondary metabolites localized in the epidermis affect the ratio of UVinduced BGF to ChlF emission in two ways a) by emitting the BGF, and b) by decreasing UV excitation of Chl through screening.

\section{Fluorosensing techniques}

Fluorosensors using UV excitation can be grouped into laboratory set-ups and lidars, although the latter can be used both outdoors and indoors.

\subsection{Laboratory fluorometry}

Laboratory spectrofluorimeters are invaluable tools for basic research on leaf fluorescence characteristics. They have been used initially in many remote sensing-oriented laboratories (table $I V$ ). For most commercial spectrofluorimeters, an adaptation must be made to allow front-face illuminationdetection geometry for the analysis of leaf samples. They have been used to measure either BGF emission spectra of intact leaves and leaf constituents $[29,92,93]$ or effects of stress on BGF emission spectra $[39,89,107]$.

Fluorescence excitation and emission spectra can be measured with laboratory spectrofluorimeters provided with a xenon lamp as excitation source and monochromators to define excitation and emission wavelengths. The most often cited types are: LS-50, Perkin Elmer; Fluorolog II, Spex; SLM-8000, SLM-Aminco; RF5001, Shimadzu.
They have been used either for basic research on leaf fluorescence characteristics $[13,29]$ or in applied research on plant responses to stress [39, $110,111,145,152]$. Less frequently, excitationemission matrices (EEM) have been used to investigate changes induced by stress on leaf fluorescence $[128,160]$. The excitation-emission matrix, also called bispectral matrix, is a fundamental laboratory technique developed by several national institutes for measurement and calibration of fluorescent materials. A three-dimensional plot is obtained, with the fluorescence radiance at the $\mathrm{z}$ axis $[128,160]$.

In principle, the excitation spectrum of a compound should follow the absorption spectrum, but in vivo this is rarely the case. In addition to nonfluorescent dissipation of some of the absorption bands, the excitation spectrum can be deformed by the inner filter effect as a result of high concentrations of the fluorophore or other compounds that re-absorb part of the spectrum. Furthermore, screening of excitation by other fluorescing or nonfluorescing compound is common.

\subsubsection{Lasers-induced fluorescence (LIF)}

Although xenon lamps can be used as excitation source in a dedicated laboratory UV fluorosensor [143], the use of pulsed UV lasers is more common, and then the technique is named laserinduced fluorescence (LIF). Pulsed lasers allow better signal-to-noise ratios. Their short pulses of high energy can induce pulsed fluorescence that can be synchronously detected. Under these conditions, the average power of the measuring beam can remain sufficiently low to be non-actinic for photosynthesis, and continuous additional actinic light can be used to drive photosynthesis. This additional light can be daylight itself. The same approach is being applied to lidars that are used outdoors, so information gained with laboratory laser fluorosensors can be used for lidar development. UV lasers such as nitrogen $(337 \mathrm{~nm})$, argon $(351 \mathrm{~nm})$ and frequency tripled Nd-YAG $(355 \mathrm{~nm})$ are the most frequently used lasers in laboratory fluorosensors (table IV). There is also a variety of potential detectors to be used, including: photo- 
Table IV. Types of fluorosensing techniques and devices (with references cited in this review).

\begin{tabular}{|c|c|c|}
\hline Technique & Specificity & References \\
\hline $\begin{array}{l}\text { Laboratory } \\
\text { spectrofluorometers }\end{array}$ & $\begin{array}{l}\text { basic research on spectral characteristics of leaves and constitu } \\
\text { emission spectra } \\
\text { excitation spectra } \\
\text { Excitation Emission Matrix (EEM) } \\
\text { time-resolved spectra }\end{array}$ & $\begin{array}{c}\text { ents } \\
\qquad \begin{array}{c}{[29,39,89,92,93,107]} \\
{[13,29,39,110} \\
111,145,152] \\
{[128,160]} \\
{[30,60,114-116]}\end{array}\end{array}$ \\
\hline Laboratory UV-LIF & $\begin{array}{l}\text { laser-induced fluorescence } \\
\text { lidar conditions but in a laboratory }\end{array}$ & $\begin{array}{c}{[11,12,18,26,32-36,73,80} \\
93,102,135,136,150,151 \\
153,156,158,159]\end{array}$ \\
\hline UV-Lidars & $\begin{array}{l}\text { outdoor measurements } \\
\text { excimer lasers }(308 \mathrm{~nm}) \text { alone or used with a Raman shifter } \\
(397 \mathrm{~nm}) \text { or with dye laser }(480 \mathrm{~nm}) \\
\text { frequency tripled Nd-YAG lasers }(355 \mathrm{~nm})\end{array}$ & $\begin{array}{c}{[\text { review } 108]} \\
{[25][24,52]} \\
{[41,52,53,62,63,107,157]}\end{array}$ \\
\hline$\tau$-UV-Lidar & $\begin{array}{l}\text { Q-switched frequency tripled Nd-YAG lasers } \\
\text { fluorescence lifetime insensitive to atmospheric perturbation } \\
\text { Only ChIF up to now }\end{array}$ & {$[28,59,113,119,147]$} \\
\hline Imaging & $\begin{array}{l}\text { Microscopy } \\
\text { Laboratory imaging systems } \\
\text { Lidar imaging systems } \\
532 \mathrm{~nm} \text { only }\end{array}$ & $\begin{array}{c}{[98,137,154]} \\
{[73,81,82,90,91,98,99,138]} \\
{[51,52,77]} \\
{[134]}\end{array}$ \\
\hline
\end{tabular}

multipliers, photodiodes, diode-arrays and charge coupled device (CCD) cameras.

The use of relative units (RFI in [32, 34-36]) can be sufficient and justified when the geometry of the measuring system is kept constant during the whole study, as in commercial fluorometers or LIF set-ups. But, to compare results gained among different research groups with different laboratory set-ups and lidars the expression of fluorescence in more universal units is needed. Two approaches are actually used in laboratory fluorometry and remote sensing to standardize the results: comparison to the Raman signal of water and the comparison to quinine sulphate fluorescence. The former is frequently used in oceanography fluorescence studies [49] but it is not well adapted to terrestrial vegetation; therefore, the use of quinine sulphate seems to be the best choice. Quinine sulphate is a fluorescence standard of known emission spectrum that is used and distributed by the United States National Institute of Standard and Technology (NIST).

\subsubsection{Time-resolved fluorescence}

As already mentioned, the use of fluorescence lifetime is an alternative to measure fluorescence yield. A special laboratory set-up dedicated to leaf fluorescence was constructed on the SA4 line of the Super-ACO storage ring at LURE in Orsay, France. This set-up uses synchrotron radiation, which is a pulsed and fully-tuneable (white) source, and time-correlated single-photon counting detection [60]. This permits measurement of timeresolved excitation and emission fluorescence spectra $[30,115]$. 
With this set-up, we performed BGF spectral and time-resolved analyses at different levels of integration within the leaf, from thylakoids to leaf pieces [30]. The proposal that BGF is emitted mainly from the epidermis was confirmed [115]. In addition, the use of the synchrotron radiation permitted us to resolve the contribution of flavin and pyridine nucleotides to BGF even in intact leaves. Nucleotides contributed mainly in the long-lived lifetime components (figure 9). After this series of works $[30,60,114-116]$, we could conclude that the BGF lifetime approach should be the way to extract the information related to the redox state of the plant cells.

\subsection{UV lidars}

A number of UV lidars, dedicated to vegetation monitoring, were successfully used for far-field fluorescence signatures evaluation (table IV). Most of the UV lidars developed in LASFLEUR use frequency tripled $\mathrm{Nd}-\mathrm{YAG}$ lasers emitting at $355 \mathrm{~nm}$ as excitation source $[41,52,53,62,63,107]$. Other devices use excimer lasers (emitting at $308 \mathrm{~nm}$ ) alone $[24,25]$ or with a Raman shifter (emitting at $397 \mathrm{~nm}$ ) [24] or with a dye laser (emitting at 480 $\mathrm{nm}$ ) [52]. When using the frequency tripled $\mathrm{Nd}$ YAG or the excimer laser, authors are able to measure BGF, RF and FRF. However, the excimer laser used with a Raman shifter or with dyes is able in principle to measure GF, RF and FRF but not BF. In addition to original papers cited, detailed description and comparisons of UV-lidar configurations can be found in [157] and [108].

Unfortunately, pump-and-probe lidars used for Chl fluorosensing [37] have still not been used for UV-excited fluorosensing. Although this is one of the most promising techniques for fluorosensing of variable ChlF, this approach has an important eye safety problem because of the need for a strong pump (actinic) flash.

\subsection{1. $\tau$-UV lidar}

One of the main advantages of using fluorescence lifetimes as a signature is that the signal is insensitive to atmospheric perturbations. The $\tau$-UV lidar developed at LURE in Orsay (France) is based on the excitation of a small portion of the canopy with a short laser pulse (35 ps duration -1 $\mathrm{mJ}$ at $355 \mathrm{~nm}$ ) provided by a Q-switched frequency tripled Nd-YAG laser. The detection is based on the use of a high speed crossed field photomultiplier and a high band-width fast transient analyzer [119]. The $\tau$-UV-LIDAR has been successfully used for remote sensing of terrestrial vegetation and detection of stress conditions in plants $[28,59$, $113,119]$. Remote sensing of plants by fluorescence lifetime measurements has been also performed with a lidar that uses a Q-switched frequency doubled $(532 \mathrm{~nm})$ or tripled $(355 \mathrm{~nm}) \mathrm{Nd}$-YAG laser with $100 \mathrm{ps}$ pulses $(100 \mu \mathrm{J}$ at $532 \mathrm{~nm}$ and 10 $\mu J$ at $355 \mathrm{~nm}$ ) [147]. This laser is based on the use of a streak camera for detection. Unfortunately, these two lidars only measure ChlF lifetimes up to now. Ideally, they should be adapted to measure both BGF and ChlF lifetimes, increasing the possible signatures for fluorosensing.

\subsection{Imaging}

Imaging can be carried out at the two extremes of the spatial-temporal scale [27]. The techniques that permit us to visualize the spatial distribution of fluorescence have been introduced both in the laboratory and in remote sensing. The first and most developed imaging device for UV-induced fluorescence is the fluorescence microscope (transmission or epi-fluorescence) which uses mercury and xenon lamps or laser excitation. Although microscopy per se is out of the scope of this review, we would like to stress the importance of the use of this technique in fluorescence work, as a complement providing information on the exact localization of fluorophores (figures 5-7). For instance, microscopy studies of UV-induced fluorescence, which is usually called autofluorescence among microscopists, showed the presence of the BGF emitted from ferulic acid esterified to cell wall polysaccharides in many organs including leaves of grasses [69]. In addition, digital imaging developed at the microscopic level can be transposed advantageously to the macroscopic level. The choice of detectors (CCD) and acquisition and 
treatment of large sets of data (computer programs) seem to be the most important points to take into account [123].

\subsubsection{Laboratory imaging}

Multi-colour fluorescence imaging at the leaf level has been reviewed recently by Buschmann and Lichtenthaler [20]. Within laboratory imaging, the fluorescence imaging system (FIS) used for whole leaves $[81,82,98]$ merits consideration. Microscopic imaging has also been used for the estimation of laser light penetration [137].

\subsubsection{Lidar imaging}

The latest achievement is the lidar multi-colour imaging $[52,77]$, which combines the lidar approach with imaging. For air-borne fluorosensing the push-broom approach [77] seems to be more appropriate because it can use single-shot measurements. Measurements can be made either at night or even better during the daytime by using gated detectors, which are sensing only in phase with pulsed fluorescence [134].

The two-photon-excitation technique, already applied in microscopy [86], might be extended to remote sensing. The advantage of this technique is that two infrared photons are combined to perform excitation to the first excited molecular level of the fluorophore, which corresponds to the absorption of a UV photon $(760 \mathrm{~nm}$ for $380 \mathrm{~nm})$. But, the main drawback of this technique is the need for a very short pulse (sub-picosecond) of very high peak power.

\section{Applications of UV-induced fluorosensing in plant sciences and agriculture}

Signatures of UV-induced fluorescence can provide important information in plant sciences for plant identification and to monitor plant growth and development. UV-induced fluorescence can also be a valuable tool in agriculture, where it can help in crop management. Among the manageable factors affecting crop productivity, water and fertil- izers are certainly the most important [67]. Pesticides play also an important role in controlling pests and pathogens which are responsible for $30 \%$ of crop losses world wide, especially under conditions where water and nitrogen are abundant. As discussed below, UV-induced fluorescence can give relevant information on these three limiting agricultural factors and a few others.

\subsection{Plant identification}

The compounds described here as being responsible for UV absorption, which contribute to BGF and to the screening of ChlF, are usually used as markers for plant chemotaxonomy [5]. It seems, therefore, obvious to apply florescence as a taxonomic signature. Unfortunately, the spectral features of phenolics, wide emission spectra and similar maximum wavelength, do not help much to achieve this goal. Still, the anatomy of leaves of different types of plants (section 2.4.1) together with the combination of different types of leaf pigments, came to the rescue for the use of fluorosensing in plant identification. As seen in figure 10 ,

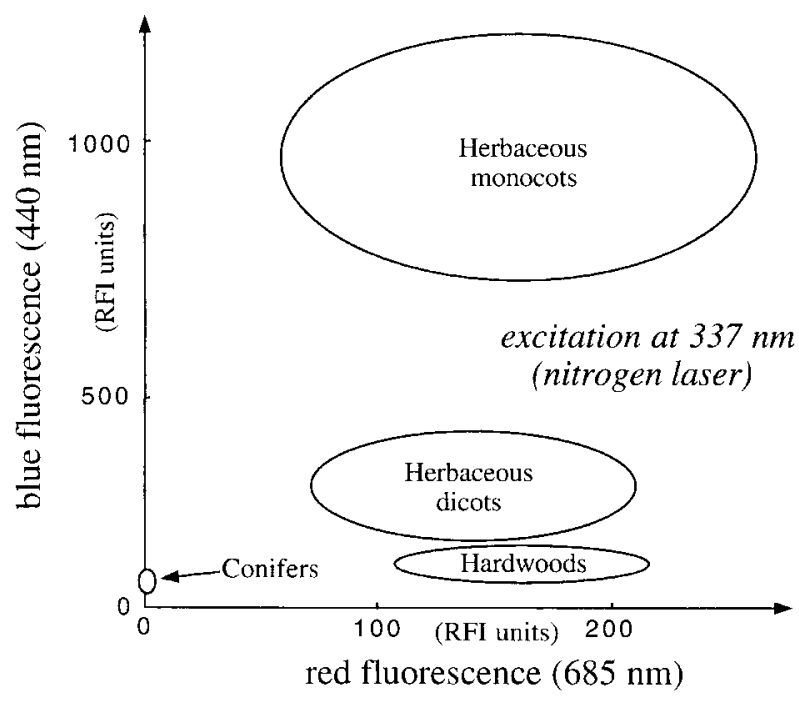

Figure 10. The use of blue-green to chlorophyll fluorescence ratio as an indicator of plant type. Graph based on data from [36]. 
adapted from the work of Chappelle and co-workers [36], the $\mathrm{BF} / \mathrm{RF}$ ratio can be used as a general plant classification criterion. The most striking feature is the very low ChlF of conifers, which is readily explained by the extremely low transmittance of the epidermis of conifer needles [45, 47].

In contrast to dicotyledonous plants, where the BGF is often lower than the RF and FRF, the BGF of monocots, especially grasses, is much higher. This probably reflects the higher content of cinnamic acids in the cell walls of the Poaceae than in those of dicotyledonous plants $[70,71]$.

\subsection{Effects of UV radiation on plants}

Most studies on the effects of UV-B radiation on leaf fluorescence reported an increase in the $\mathrm{BGF} / \mathrm{ChlF}$ ratio in treated plants $[52,111,138$, 145,152 ] (but see also [156]). As mentioned in section 2.2.2., this increased $\mathrm{BGF} / \mathrm{Ch} / \mathrm{F}$ ratio can be due to an accumulation of BGF fluorophores or to an accumulation of compounds with high UV-B absorptivities in the epidermis, which attenuates the UV excitation of Chl molecules in mesophyll cells, and, consequently, decreases the intensity of $\mathrm{UV}$-induced $\mathrm{Chl}$ fluorescence.

This screening (or blocking) of UV penetration into the mesophyll can explain most of the observations showing an increase in the $\mathrm{BGF} / \mathrm{ChlF}$ ratios in UV-treated plants when compared to control plants $[52,138]$, and also in plants exposed to full sunlight compared to those shaded $[90,145]$ or indoor plants [152]. Still, both spectral and imaging analysis showed that, in addition to epidermis screening, the increase in $\mathrm{BGF} / \mathrm{ChlF}$ ratio in UVtreated leaves can also be due to an increase in BGF itself $[52,111,138]$. This would indicate that some of the compounds accumulated under UV exposure are fluorescent. Kim et al. [82] proposed that these compounds could be epidermal flavonols, which, although not fluorescent when excited in the UV, would fluoresce green light when excited by the blue fluorescence of the epidermis.

When working on Salvia splendens, Subhash et al. [156] found that UV treatment decreases the
BGF/ChlF ratio in both young and old plants. Although differing from most other results described above, this work also showed that the F450/F730 ratio was the most reliable indicator of UV damage, and that ChlF was not affected by UV treatment, because ChlF excited by visible light (485 nm) was not changed in treated leaves. The authors concluded that changes in UV-excited spectra after UV treatment of leaves must be attributed to a change in light penetration through the leaf and/or to different energy transfer processes among the leaf pigments [156].

\subsection{Plant growth and development}

The Karlsruhe group has reported on several occasions that $\mathrm{BGF}$ is higher in leaves that have lower Chl contents. For instance, an increased BGF was recorded in senescent beech leaves [89] and etiolated wheat leaves $[151,152]$. Chappelle et al. [35] also recorded an increased BGF in senescent soybean leaves. Since the $\mathrm{Chl}$ content and the content of other UV-absorbing pigments depend on leaf age (or stage of development) and on the light that the leaf has experienced up to the time of analysis, the increased BGF cannot be the consequence of a decreased re-absorption effect by $\mathrm{Chl}$ alone. Although the re-absorption effect on BGF cannot and should not be excluded, most of the BGF comes from the leaf surface (less than $10 \%$ comes from the mesophyll) and therefore the $\mathrm{Chl}$ re-absorption effect is certainly minor as compared to the effect of UV-excitation screening by the UVabsorbing pigments of the epidermis. Therefore, the $\mathrm{BGF} / \mathrm{ChlF}$ (or F440/F690) ratios reported in greening and senescent leaves can be more influenced by changes in the epidermis, like those described for nitrogen deficiency [73], than by changes in $\mathrm{Chl}$ content.

In maize internodes of varying maturity, the ferulic acid ester levels increased from younger to intermediate internodes and then slightly declined in older, lignifying internodes [117]. This increase in ferulic acid content with age could at least partly explain the results of the Karlsruhe group [73] showing an increase in the fluorescence blue to red 


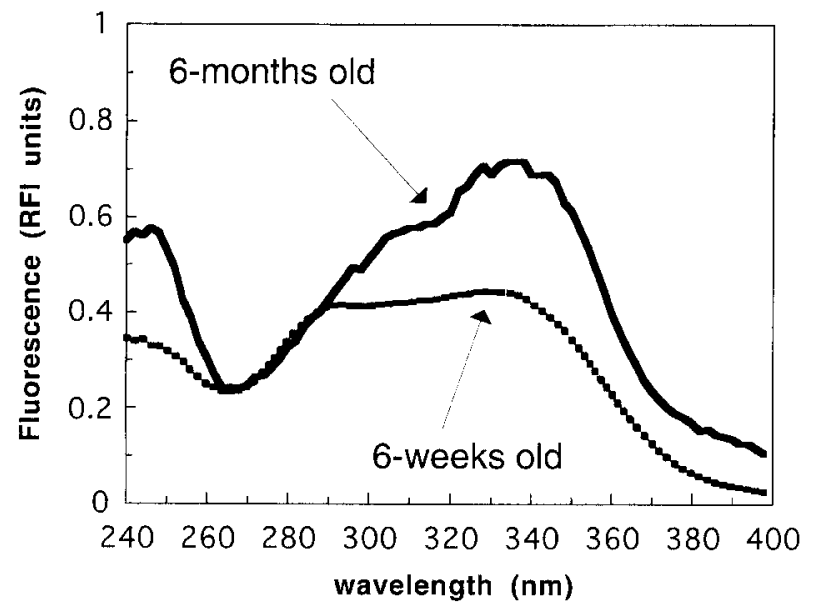

Figure 11. Comparison of the excitation spectra of BGF of a 6-week-and a 6-month-old sugar beet (Beta vulgaris L.) leaf. Spectra were recorded on the Super-ACO set-up at the emission maxima of leaf $\mathrm{BGF}$, at $3{ }^{\circ} \mathrm{C}$ to maximize epidermal fluorescence. Spectra were normalized at the maximum number of common points. RFI - relative fluorescence intensity.

ratio from young to mature maize leaves. An increase in UV-absorbing flavonoids will also bring an increase in the $\mathrm{F} 440 / \mathrm{F} 690$ ratio. This could be assessed by measuring the F690 decrease, which was not presented in the cited paper, or by estimating the decrease in leaf epidermal transmittance for UV light, as proposed by Bilger et al. [8]

Accumulation of ferulic acid esters can probably also explain the changes in the excitation spectrum of BGF in ageing sugar beet leaves (figure 11). In 6-month-old leaves, compared to young 6-weekold leaves, there is a preferential increase in excitation at $330 \mathrm{~nm}$, with a shoulder at 310 , which is characteristic of fluorescence excitation spectra of ferulic acid esters.

\subsection{Mineral deficiencies}

Several studies have already indicated the potential usefulness of UV-induced fluorescence for the detection of nutrient stresses in plants, especially for nitrogen deficiency. In general, N-deficient plants show large increases in the $\mathrm{BF} / \mathrm{ChlF}$ ratio compared to unstressed plants [20, 32, 39, 73], although there is one exception where the opposite was observed [109]. The increase in the $\mathrm{BF} / \mathrm{ChlF}$ ratio due to $\mathrm{N}$ deficiency usually occurs before the loss of leaf chlorophyll content and thus before the increase in the F685/F735 ratio. This implies that the increase in the $\mathrm{BF} / \mathrm{ChlF}$ ratio in $\mathrm{N}$-deficient plants is likely due to an accumulation of phenolic or flavonoid compounds absorbing UV light in leaf epidermis (decreased transmittance to UV), thereby decreasing the excitation of Chl molecules in the mesophyll by UV light.

Besides a decrease in ChIF emission, $\mathrm{N}$ deficiency can have different effects on the BF yield depending on the plant growth conditions. In studies using greenhouse plants (maize and soybean), it was reported that $\mathrm{N}$ deficiency either decreased $[32,39]$ or increased [20] the BGF yield. In the latter case, an accumulation of plant hydroxycinnamic acids (ferulic acid) emitting blue fluorescence could contribute to the observed increase of the $\mathrm{BF} / \mathrm{ChlF}$ ratio. In contrast to greenhouse plants, similar BF yields were observed in $\mathrm{N}$-deficient and control maize plants grown in the field [73, 109]. The different effects of $\mathrm{N}$ deficiency on BF emitted by outdoor and greenhouse plants are probably due to the larger amount of phenolic metabolites naturally found in leaf epidermis of outdoor plants $[105,106]$, which would tend to mask the effects of $\mathrm{N}$ deficiency. Consequently, the effects of $\mathrm{N}$ deficiency on BF can be more evident in greenhouse or shade plants than in outdoor plants grown under full sunlight.

The applications of fluorosensing for the detection of nutrient deficiencies other than nitrogen stress are more scarce. Still, shortage of potassium can have a very pronounced effect on UV-induced fluorescence. In contrast to $\mathrm{N}$ deficiency, Chappelle et al. [35] observed a large decrease in the $\mathrm{BF} / \mathrm{Ch} / \mathrm{F}$ ratio in $\mathrm{K}$-deficient maize compared to control plants. In that study, K-deficiency strongly enhanced ChlF emission but did not significantly alter the BGF emission. These results therefore suggest that $\mathrm{K}$ deficiency altered the UVinduced fluorescence by decreasing the UV-screening effect of epidermis in maize leaves. 
Effects of other mineral deficiencies on UVinduced fluorescence emission were also investigated but so far only inconsistent data have been reported. For example, Chappelle et al. [35] and Heisel et al. [73] observed that iron deficiency in maize plants significantly increased and decreased the $\mathrm{BF} / \mathrm{ChlF}$ ratio, respectively. Chappelle et al. [35] reported a decrease in BGF yield in Fe-deficient maize, whereas Morales et al. [114] observed the opposite in Fe-deficient sugar beet mesophylls. Finally, a dramatic increase in the $\mathrm{BF} / \mathrm{ChlF}$ ratio was observed in old leaves of $\mathrm{Mg}$-deficient maize but no significant effects were seen in young and mature leaves [73].

These various observations indicate that several factors, such as leaf age and position, species, growth conditions, leaf temperature, and water status (see below), can strongly influence the impacts of nutrients deficiencies on UV-induced fluorescence emission. To demonstrate a clear and specific effect of a given nutrient deficiency on UVinduced fluorescence, relevant growth and physiological parameters should be measured and compared to several fluorescence signatures. A single fluorescence ratio such as the BF/ChlF or the F685/F735 ratios may not provide at this stage reliable information on plant nutrient status. Instead, a combination of fluorescence parameters such as the fluorescence global vegetation index (FGVI) [27], the leaf epidermal transmittance of UV radiation, estimated by the ratio of ChlF yields induced by UV and blue excitation lights [8], and also the F685/F735 ratio, can provide a basic diagnosis of the plant nutrient status at a given developmental stage. These fluorescence parameters would allow one to determine whether a high $\mathrm{BGF} / \mathrm{ChlF}$ ratio induced by nutrient shortage is the consequence of 1) an accumulation of fluorescing phenolics contributing to the BGF increase, 2) accumulation of non-fluorescent phenolics, which by screening UV excitation of $\mathrm{Chl}$ molecules decrease ChlF yield, or finally 3) a loss of leaf Chl content thereby decreasing BGF re-absorption.

Moreover, the use of fluorescence imaging techniques, although not applicable in the field for rapid analysis, can provide useful information concerning the spatial resolution of fluorescence emis- sion and therefore help to identify nutrient deficiencies $[20,73]$.

A method using solar blind excitation and detection (both in UV) [39] has also been proposed for the estimation of nitrogen deficiency by monitoring protein fluorescence in the leaf. Unfortunately, protein fluorescence induced by $\mathrm{UV}-\mathrm{B}$ radiation and emitted in the UV-A, will be very much affected by the fluorescence of lignin and lignin precursors [87], and probably other phenylpropanoids.

\subsubsection{The carbon/nutrient balance hypothesis}

Up to now, the relationship between nutrient deficiencies and the corresponding changes of UVinduced fluorescence has remained mostly empirical and its physiological basis is poorly understood. An interesting approach to explain the changes in UV-induced fluorescence in nutrientdeficient plants is the carbon/nutrient balance hypothesis that is widely accepted by chemical ecologists $[3,19,129]$. According to this hypothesis, excess of fixed carbon relative to the plant's resources (high carbon/nutrient ratio) stimulates the shikimate pathway and therefore the production of plant phenolics $[129,169]$. Increases in total plant phenolics are generally observed in nutrientdeficient plants $[19,129,169]$. In rice plants, the most sensitive response was observed for $\mathrm{N}$ deficiency, which was characterized by noticeable increases in $p$-coumaric acid and ferulic acid levels [38]. These responses are consistent with the increases in the BG/ChlF ratios observed in N-deficient plants from other studies $[20,32,39,73]$.

All these findings led us to propose in 1995 a new vegetation index based on fluorescence measurements - the fluorescence global vegetation index (FGVI) [27]. This proposal to use a normalized ratio (ChlF - BGF)/(ChlF + BGF) as a global vegetation index of nutrient shortage and presence of stress (figure 12) is now strengthened by the knowledge of the UV-screening effect of the secondary metabolites described above. Low FGVI or high simple BGF/ChIF ratio is a global indication of nutrient shortage induced either by an accumulation of fluorescing phenolics, which contribute to BGF increase, or accumulation of non-fluorescent phenolics, which by screening UV excitation of 


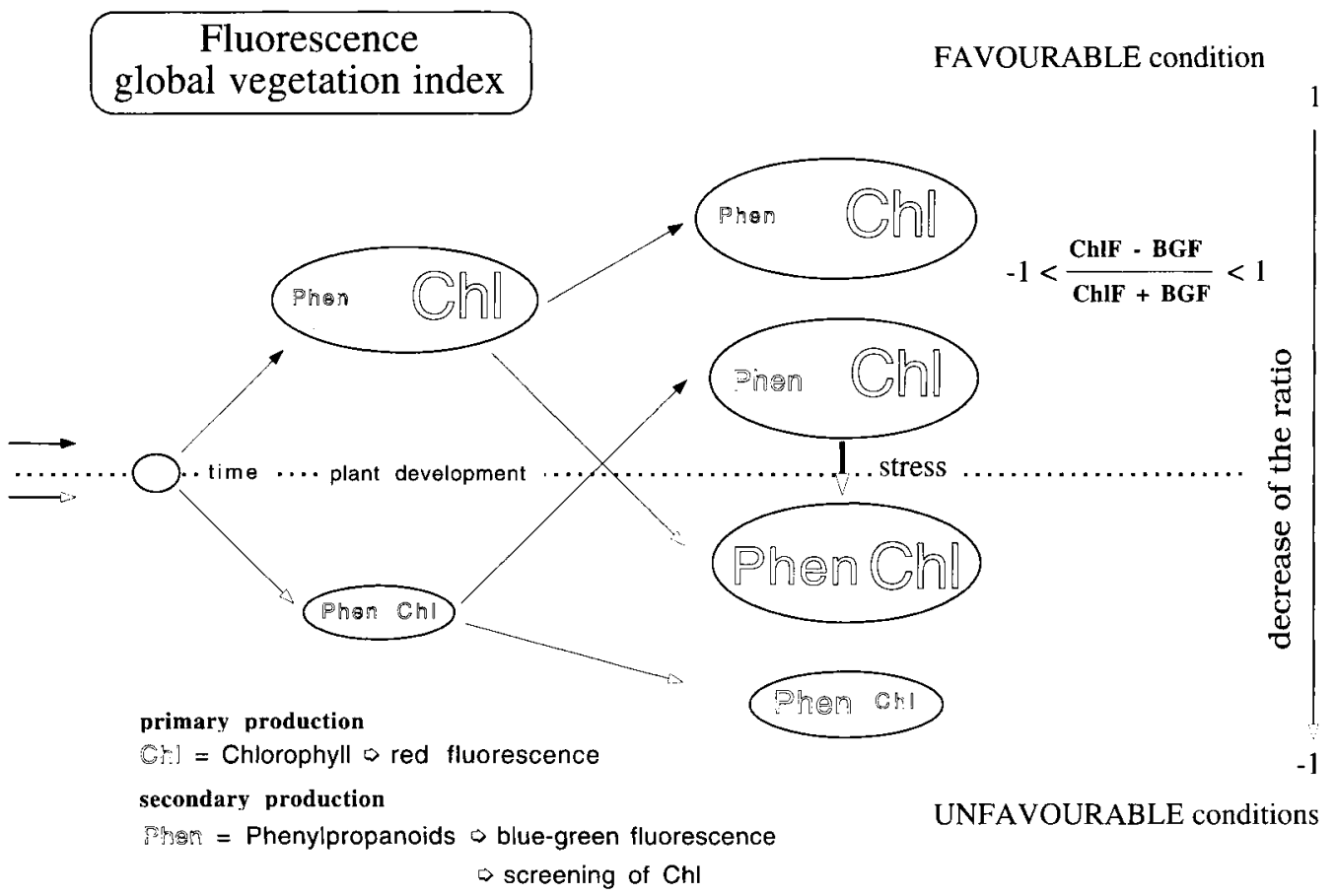

Figure 12. Fluorescence global vegetation index (FGVI). The size of oval surfaces symbolizes leaf development and expansion, and the size of abbreviations they encircle, Chl for chlorophyll, and Phen for phenylpropanoids, represents their respective content in the leaf.

Chl, contribute to the ChlF decrease. The FGVI should be interesting on a regional and global level, like the reflectance signature NDVI, but its practical application will depend on the development of air-borne lidars at the regional level and passive fluorosensing in the Fraunhofer lines for the global level [120].

\subsection{Water stress}

Like nitrogen, water availability will influence the development of plants and their fluorescence characteristics. Therefore, the concept of FGVI (figure 12) incorporates the effect of water stress on the long-term scale. Although the most prominent characteristics of UV-induced fluorescence of leaves under water stress is an increase in $\mathrm{BGF} / \mathrm{ChlF}$ ratio, it might not be of the same origin on the short- and long-term scales. Long-term drought will certainly modify the fluorescence characteristics by inducing the development of xeromorphic leaves [9], but this aspect has not yet been studied.

Short-term water stress was studied in the laboratory under more or less physiological conditions. The most drastic treatment, which consisted in drying detached leaves, showed an increase in BGF with water loss in maple leaves (Acer pseudoplatanus L.) [160], olive leaves (Olea europea L.) [18], and in pine needles (Pinus sylvestris L.) [100]. In maple leaves, the BF/RF ratio increased from 0.9 to 6.1. From the EEM, it can be seen that the $\mathrm{BF} / \mathrm{RF}$ ratio increase was primarily due to an increase in BF; therefore, an accumulation of blue fluorescing compound(s) must be involved. The small increase in RF/FRF (F695/F735) (0.8-1.1) could probably be explained by an increase in the 
reflectance ratio (R685/R730) during the drying of leaves.

In the case of olive leaves, the most striking effect was the increase in the GF (F550) [18]. Bongi and colleagues [12, 13] showed that in olive leaves BGF correlates with the build-up of epicuticular wax in leaves grown under strong light or under slowly developing drought stress. They concluded that the BGF fluorophores are flavonoids which are dispersed in the epicuticular wax. These flavonoids would have to be aglycones [172] and their deposition on the leaf surface would doubly increase the $\mathrm{BGF} / \mathrm{ChlF}$ ratio, by screening the excitation of ChlF and by increasing BGF.

In soybean (Glycine $\max \mathrm{L}$.), an overall increase in both BGF and ChlF was observed under drought. This fluorescence increase was not associated with any substantial change in reflectance [128], and was more pronounced under chronic than acute stress. This behaviour of water-stressed soybean leaves had already been noted in the work of Chappelle et al. [35], who recorded in addition a large increase in the F530 band. This GF increase suggests an accumulation of green fluorescing compounds. Another possibility would be an increase in apoplastic $\mathrm{pH}$, causing a reversible shift from blue to green fluorescence [69]. Still, the concomitant increase in both BGF and ChlF implies the presence of an optical effect or a decreased screening of UV excitation. A decrease in cellular water content (cell size) can also influence epidermal transmittance for UV radiation (excitation).

A similar effect of water stress was seen in tobacco leaves (Nicotiana tabacum L.), using fluorescence imaging [90]. Under medium water stress all fluorescence bands were increased, but the increase was larger for $\mathrm{BF}$ than $\mathrm{RF}$ and for $\mathrm{GF}$ compared to $\mathrm{BF}[90]$. It should be noted that the increase in $\mathrm{BF} / \mathrm{RF}$ ratio was induced below a threshold value of $84 \%$ relative leaf water content.

In their work on maize (Zea mais L.), Dahn and coworkers [41] showed that the $\mathrm{BF} / \mathrm{RF}$ ratio increased reversibly under drought stress. The changes in RF/FRF ratio, which decreased under drought stress, were much smaller, but still noticeable. Fluorescence changes were present both at the leaf and canopy level, where they tend to be obscured by the heterogeneity in leaf development. For leaves of the same age and same chlorophyll concentration, the small decrease in RF/FRF ratio can be, at least partially, explained by the build-up of non-photochemical quenching during the day in drought-stressed maize [28]. FRF is less affected by non-photochemical quenching than RF [57]. Although this non-photochemical quenching of ChlF can contribute to the increase in BF/RF ratio, it seems that the increase in this ratio is too large to be explained by a RF decrease alone. Indeed, the authors reported that the BF increased under drought conditions. The increase in BF was seen both in individual leaves and canopies; therefore, it cannot come from the curling of leaves which would expose the abaxial side to excitation. In the study cited, an increase in blue fluorophore content or screening of ChlF must be present in stressed leaves. Still, especially for maize leaves that have special bulliform cells which react to water loss [14], curling of leaves under water stress can have an important effect on canopy fluorosensing.

We can conclude that water stress induces an overall increase in fluorescence in many plants which could be explained by 1) a change in optical properties of the leaf (increased epidermal transmittance to UV light), 2) an accumulation of blue or green fluorophores, and 3) an increase in the apoplastic $\mathrm{pH}$. The accumulation of blue-green fluorophores, or their better exposure to excitation, can be related to xeromorphic transformations induced in leaves in long-term stresses [9], but still the nature of these blue and green fluorophores remains elusive.

\subsection{Temperature}

Leaf temperature is another intrinsic leaf factor, which often changes concomitantly to water stress development. It is very important to consider leaf temperature when interpreting $\mathrm{BGF}$ changes. Results from work carried out at LURE in Orsay (France) clearly demonstrated that BGF intensity increases reversibly as leaf temperature decreases from 33 to $3^{\circ} \mathrm{C}[12,13,115,116]$. The extent of 
$\mathrm{BGF}$ variation may be as much as $-5 \%$ per ${ }^{\circ} \mathrm{C}$ [116], but changes of -1 to $-3 \%$ per ${ }^{\circ} \mathrm{C}$ are more typical, depending on plant species $[12,13]$.

Morales et al. [116] observed that in contrast to $\mathrm{BGF}$, a decrease in leaf temperature from 33 to $3^{\circ} \mathrm{C}$ did not affect the ChIF yield. As a consequence, the blue to red fluorescence ratio increased with decreasing temperature. This implies that leaf temperature should be monitored, in order to determine whether a change in blue to red fluorescence ratio reflects a variation in leaf temperature or the presence of another stress. For sugar beet leaves, it is the fast ( $0.3 \mathrm{~ns})$ and medium ( $1 \mathrm{~ns}$ ) lifetime components which are the most sensitive, with a thermal sensitivity exceeding $10 \%$ increase per ${ }^{\circ} \mathrm{C}$ of decrease in temperature [116]. The fluorophore responsible for this high thermal sensitivity is apparently located in the epidermis [116], but its chemical nature is still unknown.

On the other hand, it was demonstrated that in leaves exposed to moderate light $(100-150 \mu \mathrm{mol}$ photon $\left.\cdot \mathrm{m}^{-2} \cdot \mathrm{s}^{-1}\right)$ under chilling temperature $\left(4^{\circ} \mathrm{C}\right)$, $\mathrm{ChlF}$ yield showed a complex time-dependent behaviour, increasing and then decreasing during the chilling treatment $[1,2,163]$. Here, the presence of moderate light while the leaf temperature was decreased could be responsible at least in part for the temperature dependence of ChlF. In this case, changes in photochemical and non-photochemical quenching in illuminated leaves submitted to decreasing temperatures could explain the variations of ChlF.

In the field, water stress is accompanied by an increase in leaf temperature due to closure of stomata and decreased transpiration. This will certainly decrease BGF, but the extent of the change will depend on plant species. The BGF of Gramineae such as Zea mais L., Lolium perenne L. and Triticum aestivum L. are particularly sensitive to temperature $[12,13]$. This could be related to the presence of large contents of ferulic acid in these species in particular and in this plant family in general [70]. Thus, properly calibrated, the leaf BGF, and the $\mathrm{BGF} / \mathrm{ChlF}$ ratio, could be used as a remote sensing thermometer [116].

\subsection{Responses to pathogens}

The influence of plant pathogens on UV-induced fluorescence has attracted scant attention in the fluorosensing community compared to the importance of the issue. The notable exemption is the work of Lüdeker at al. [107] who investigated the effect of fungal infection on a few representatives of monocotyledonous and dicotyledonous plants. In all cases the increase in BF/FRF ratio was the most noticeable signature. The authors explained the increase by the contribution of fungus fluorescence to the blue band, especially in the case of mildew on apple (Malus sylvestris L.) leaves. However, it is likely that the plant response to the presence of the pathogen can also contribute to the increase in BGF. There are now several examples in the literature to support the idea that plant response to pathogen elicitors involves the production of many phenolic phenylpropanoids known as phytoalexins $[7,43,50,85,122]$. Ultrastructural and cytochemical studies have demonstrated the accumulation of phenolic compounds in the walls of epidermal cells that are in close contact with the invading fungal hyphae $[6,7,42]$. These phenolic compounds could restrain fungal colonization by either increasing the mechanical strength of the host cell walls at sites of potential fungal entry or causing growth inhibition of the fungus [7].

As for the identification of nutrient deficiencies, fluorescence imaging techniques are valuable tools to study plant responses to pathogens, as illustrated by the work of Buschmann and Lichtenthaler [20] who reported effects of insects on leaf BGF. Even on black and white images of UV-induced BGF, small punctures made by tobacco flies on leaves can be visualized. The strong increase of BGF was suggested to result from the accumulation of fluorescent phytoalexins (stilbenes) around the lesion. In the case of tobacco leaves, a recent study rather indicated that the accumulation of the very fluorescent coumarin scopoletin was more likely (Cerovic and Latouche, unpublished results). In the same report of Buschmann and Lichtenthaler [20], mite attacks on bean (Phaseolus vulgaris L.) plants were seen as large increases in $\mathrm{BF}$, leading to an increase in the F440/F690 ratio, and as slight 
increases in the $\mathrm{F} 690 / \mathrm{F} 740$ ratio. This indicates that the mites suck the chloroplasts from the abaxial side, and therefore the loss of ChIF contributes to the increase in $\mathrm{BGF} / \mathrm{ChlF}$ ratio seen from the adaxial side.

\subsection{Fluorosensing and agriculture}

Plant fluorescence signature can be changed by many environmental factors and often in the same direction. As summarized by Buschmann and Lichtenthaler [20] seven types of plant stresses ranging from $\mathrm{N}$ deficiency to photoinhibition induce a large increase in the F440/F690 ratio. Plant fluorosensing may therefore suffer from a lack of specificity in response to these stresses. There is a need to better understand the physiological significance of these changes, to know the impacts of environmental stresses on intrinsic leaf properties and on the concentrations of the potential fluorophores and their location in the leaf. This knowledge will suggest the use of a combination of fluorescence signatures (different ratios or intensities) in order to provide a reliable assessment of the plant general fitness from UV-induced leaf fluorescence.

Effective stress detection and discrimination techniques would be very welcome for a number of purposes in agricultural crop production and protection. Stresses can stem from biotic or abiotic factors but only few of them can be effectively tackled by the producer. Indeed, climatic causes are most important but out of anyone's control. Pest and fertilization management are therefore the primary targets of fluorosensing techniques.

For example, there are approximately 11 million tons of nitrogen fertilizer applied per year to crops on US soils alone, which costs the American farmer over 5 billion dollars annually. Nutrient availability is ranked second only to rainfall as the most important requirement for profitable crop production. Nitrogen assimilation is the most important plant nutritional process that a farmer manages in cultivated crops. Management of nitrogen fertilizers represents therefore an important aspect of modern crop production that has econom- ic and environmental consequences: high nitrogen inputs are required for the acquisition of profitable crop yields but overfertilization can lower crop quality attributes and cause pollution of surface and underground waters. Despite its overwhelming importance, nitrogen fertilizer localized management has not yet been properly addressed because of the hardly predictable behaviour of its natural release from soil. There is a need for accurate assessment of plant nitrogen requirements based on rapid screening techniques which could be used for on-the-go variable rate nitrogen fertilizer applications with highly precise spatial details instead of uniform applications as a function of the mean site condition. This is 'precision agriculture' applied to nitrogen management.

What is most needed now are case studies with robust signatures. The nitrogen effect will depend on the crop type. In soybean, additional nitrogen is useful only from the seed filling phase till maturity, because in earlier phases of development it will benefit from symbiotically fixed nitrogen, which stops at the seed filling phase. High nitrogen can even be detrimental, for example in sugar beet where too large leaves (the above ground mass) can deplete the sugars from the roots, which will be finally harvested.

ChIF represents an excellent probe of photosynthetic efficiency, which can directly or indirectly reflect the impacts of environmental stress on plants. However, it is important to keep in mind that crop productivity is the product between leaf photosynthetic activity and the photosynthetic leaf area. In many instances, cessation of leaf growth is the first physiological response to environmental stress, even before leaf photosynthetic rate is affected [165, 168]. Therefore, a powerful indicator of the physiological state of plants and the effects of environmental factors on them should be able to monitor both photosynthetic efficiency and leaf growth potential.

Vine growing is one of the activities that could soon profit from fluorosensing. Resveratrol, which is a good BGF fluorophore [42], and its oligomeric derivatives viniferins from the stilbene family, are accumulated in grapevine leaves (Vitis vinifera L.) 
in response to fungal attack by Botrytis cinerea [148] and Plasmopara viticola [42, 148]. BGF could therefore be used as an early indication of infection in grapevine. Likewise, scopoletin will accumulate in tobacco (Nicotiana tabacum L.) leaves upon pathogen attack. This accumulation could be seen either as an increase in BGF yield or lifetime ( $\mathrm{F} 450$ of healthy leaves is $0.7 \mathrm{~ns}$, whereas F450 for pure scopoletin is $2.7 \mathrm{~ns}$; Cerovic, unpublished results).

In the visible part of the spectrum, our eyes and experience are often sufficient and better than any artificial detector to evaluate the state of a crop. Therefore, to be useful for remote sensing of vegetation, fluorescence or any other signature must fulfil one or several of the following criteria: 1) to respond to the presence of stress before the appearance of visible symptoms, in order to be able to alleviate the causes of the stress before irreversible damage occurs to the plant; 2) to be an invisible signal to the human eye, present in the UV or IR part of the spectrum, and often complementary to visible signatures; 3 ) amiable for automatic treatment for machine vision, and possibility to be used for feed-back action; 4) even when present in the visible part of the spectrum, the signature should be accessible from a great distance in order to be useful at the regional level. Vegetation fluorescence fulfils several of the above criteria. Complex signatures like the photo-induced variable ChlF, which is linked to the efficiency of the photosynthetic apparatus, can, in addition to above criteria, bring a non-destructive estimation of plant functioning. Thus, there are several types of possible fluorosensing approaches including devices with fixed position in the field for continuous crop monitoring, sampling by hand-held devices, truckmounted devices and crop monitoring by aircraftmounted lidars, all using a specific signature or combination of signatures. For example, a first trial was made to estimate the harvest date for lettuce based on BGF with fixed position in the field [136].

An important aspect of the UV-induced fluorescence should be mentioned at the end. In addition to remote sensing as defined above, all mentioned fluorescence signatures can also be used under controlled conditions in the laboratory or greenhouses for plant selection in breeding or genetically modified organisms (GMO) programmes. It is a non-destructive and non-intrusive technique that can be used in automated procedures or on large surfaces in order to analyse a large number of genotypes under different environmental conditions. This is the great advantage of fluorosensing: being just a measure of emitted light, the same fluorescence signal, signature and measuring device can be used in all aspects of research, amelioration, agriculture and environment issues involving vegetation.

\section{Concluding remarks}

Linking physiological attributes and functioning of cultures with agronomy and crop yield remains a major challenge for plant researchers. UVinduced fluorescence in particular, and plant fluorescence in general, can contribute to this endeavour. Fluorescence provides a means for studying physiological responses to environmental stresses at sample sizes relevant to understanding variations within a population under field conditions. It provides a means of linking processes ranging from biophysical and biochemical reactions in the cell to crop dynamics.

It is now clear that agricultural production is currently unsustainable. Indeed, human activities, as they are now conducted, appear to be approaching the limits of the Earth's capacity. The main challenge for the immediate future is to expand agricultural production at a rate exceeding population growth. This must involve simultaneous replacement of destructive agricultural practices with more benign ones. A list of potential improvements should include: 1) conserving soil and water, with special priority to combating erosion; 2) maintaining biodiversity; 3 ) improving pest control; 4) developing new crop strains with increased yield, pest resistance, and drought tolerance; 5) reducing dependency on pesticides and herbicides. Fluorosensing has its role to play towards this goal for sustainable development by its implementation 
into precision agriculture (integrated farming) and plant monitoring. UV-induced fluorosensing can help water resources and mineral nutrition management, pollution and pest control and general survey of vegetation. Once the UV-induced fluorosensing is implemented in machine vision, the fluorescence signatures described in this paper will be used for: 1) plant recognition for automatic weed treatment; 2) plant recognition for geographic survey and crop control (regional scale); 3) detection of nutrient deficiencies for precision crop mineral nutrition; 4) early detection of parasites for early and precise treatment; 5) early detection of water stress; 6) indirect estimations of soil characteristics such as compaction, $\mathrm{pH}$ and presence of heavy metals and aluminium. Like any other newly developed technique, UV-induced fluorosensing might tend to claim that it can solve, or at least tackle, all the problems raised by agriculture and environment. With time, research and applications, the optimal domains and related signatures will be selected in competition with other techniques with respect to cost, efficiency and robustness. In addition, the knowledge accumulated by plant fluorosensing during the last 15 years should allow us to change from mainly signature-oriented research to plant species- and plant function-oriented research.

Acknowledgments: We are indebted to Sylvie Meyer for discussions on plant anatomy, Sonja Yakovlev for microscopy, and Gwendal Latouche for help with fluorescence measurements. The authors also wish to thank Dr C. Buschmann, Dr K.P. Günther, Dr J. Johansson, Dr H.K. Lichtenthaler, Dr E.M. Middleton, Dr D.T. Krizek, Dr R. Reuter, Dr J. Snel, Dr N. Subhash, Dr Y. Saito and Dr A.F. Theisen for preprints of their work and information. F.M. was supported by a contract from the Spanish Ministry of Education and Culture, and G.S. by an operative grant from NSERC of Canada. Z.G.C. and I.M. wish to acknowledge the support of the CNRS through the GDR 1536 'FLUOVEG'.

\section{References}

[1] Agati G., Mazzinghi P., di Paola M.L., Fusi F., Cecchi G., The F685/F730 chlorophyll fluorescence ratio as indicator of chilling stress in plants, J. Plant Physiol. 148 (1996) 384-390.
[2] Agati G., Mazzinghi P., Fusi F., Ambrosini I., The F685/730 chlorophyll fluorescence ratio as a tool in plant physiology: response to physiological and environmental factors, J. Plant Physiol. 145 (1995) 228-238.

[3] Baas W.J., Secondary plant compounds, their ecological significance and consequences for the carbon budget, in: Lambers $\mathrm{H}$. (Ed.), Causes and Consequences of Variation in Growth Rate and Productivity of Higher Plants, SPB Academic Publishing, The Hague, 1989, pp. 313-340.

[4] Ball M.C., Butterworth J.A., Roden J.S., Christian R., Egerton J.J.G., Applications of chlorophyll fluorescence to forest ecology, Aust. J. Plant Physiol. 22 (1995) 311-319.

[5] Bate-Smith E.C., The phenolic constituents of plants and their taxonomic significance, J. Linn. Soc. (Bot.) 58 (1962) 95-175.

[6] Benhamou N., Bélanger R., Benzothiadiazolemediated induced resistance to Fusarium oxysporum $\mathrm{f}$. sp. radicis-lycopersici in tomato, Plant Physiol. 118 (1998) 1203-1212.

[7] Benhamou N., Bélanger R.R., Induction of systemic resistance to Pythium damping-off in cucumber plants by benzothiadiazole: ultrastructure and cytochemistry of the host response, Plant J. 14 (1998) 13-21.

[8] Bilger W., Veit M., Schreiber L., Schreiber U., Measurement of leaf epidermal transmittance of UV radiation by chlorophyll fluorescence, Physiol. Plant. 101 (1997) 754-763.

[9] Bolhar-Nordenkampf H.R., Shoot morphology and leaf anatomy in relation to photosynthesis, in: Coombs J., Hall D.O., Long S.P., Scurlock M.O. (Eds.), Techniques in Bioproductivity and Photosynthesis, Pergamon Press, Oxford, 1985, pp. 107-117.

[10] Bolhar-Nordenkampf H.R., Long P.S., Baker N.R., Oquist G., Schreiber U., Lechner E.G., Chlorophyll fluorescence as a probe of the photosynthetic competence of leaves in the field: a review of current instrumentation, Funct. Ecol. 3 (1989) 497-514.

[11] Bongi G., Goulas Y., Moya I., Schmuck G., Détéction simultanée dans les bandes bleue et rouge de la fluorescence induite par laser des végétaux, in: Physical Measurements and Signatures in Remote Sensing, ESA SP-319, Courchevel, France, 1991, pp. 719-722.

[12] Bongi G., Palliotti A., Rocchi P., Moya I., Goulas Y., Blue-green fluorescence excited by UV laser on leaves of different species originates from cutin and 
is sensitive to leaf temperature, Plant Cell Environ. 17 (1994) 777-780.

[13] Bongi G., Palliotti A., Rocchi P., Moya I., Goulas Y., Spectral characteristics and a possible topological assignment of blue green fluorescence excited by UV laser on leaves of unrelated species, Remote Sens. Environ. 47 (1994) 55-64.

[14] Bowes B.G., Structure des plantes, Inra, Paris, 1998.

[15] Briantais J.-M., Dacosta J., Goulas Y., Ducruet J.-M., Moya I., Heat-stress induces in leaves an increase of the minimum level of chlorophyll fluorescence, $\mathrm{F}_{\mathrm{o}}$ : A time resolved analysis, Photosynth. Res. 46 (1996) 189-196.

[16] Briantais J.-M., Merkelo H., Govindjee, Lifetime of the excited state $(t)$ in vivo. III. Chlorophyll during fluorescence induction in Chlorella pyrenoidosa, Photosynthetica 6 (1972) 133-141.

[17] Briantais J.-M., Vernotte C., Krause G.H., Weis E., Chlorophyll $a$ fluorescence of higher plants: chloroplasts and leaves, in: Govindjee, Amesz J., Fork D.C. (Eds.), Light Emission by Plants and Bacteria, Academic Press, Orlando, 1986, pp. 539-583.

[18] Broglia M., Blue-green laser-induced fluorescence from intact leaves - Actinic light sensitivity and subcellular origins, Appl. Opt. 32 (1993) 334-338.

[19] Bryant J.P., Chapin F.S.I., Reichardt P.B., Clausen T.P., Response of winter chemical defense in Alaska paper birch and green alder to manipulation of carbon/nutrient balance, Oecologia 72 (1987) 510-514.

[20] Buschmann C., Lichtenthaler H.K., Principles and characteristics of multi-colour fluorescence imaging of plants, J. Plant Physiol. 152 (1998) 297-314.

[21] Butler W.L., Kitajima M., Fluorescence quenching in Photosystem II of chloroplasts, Biochim. Biophys. Acta 376 (1975) 116-125.

[22] Caldwell C.R., Ultraviolet-induced photodegradation of cucomber (Cucumis sativus L.) microsomal protein tryptophanyl residues in vitro, Plant Physiol. 101 (1993) 947-953.

[23] Caldwell M.M., Solar UV irradiation and the growth and development of higher plants, in: Giese A.C. (Ed.), Photophysiology, Academic Press, New York, 1971, pp. 131-171.

[24] Cecchi G., Mazzinghi P., Pantani L., Valentini R., Tirelli D., De Angelis P., Remote sensing of chlorophyll $a$ fluorescence of vegetation canopies: 1 . Near and far field measurement techniques, Remote Sens. Environ. 47 (1994) 18-28.
[25] Cecchi G., Pantani L., Breschi D., Tirelli D., Valmori G., FLIDAR: a multipurpose fluorosensorspectrometer, EARSeL Adv. Remote Sens. 1 (1992) $72-78$.

[26] Cerovic Z.G., Bergher M., Goulas Y., Tosti S., Moya I., Simultaneous measurement of changes in red and blue fluorescence in illuminated isolated chloroplasts and leaf pieces: The contribution of NADPH to the blue fluorescence signal, Photosynth. Res. 36 (1993) 193-204.

[27] Cerovic Z.G., Goulas Y., Camenen L., Guyot G., Briantais J.-M., Morales F., Moya I., Scaling fluorescence signals from the chloroplast to the canopy level, in: Guyot G. (Ed.), Photosynthesis and Remote Sensing, EARSeL, Paris, Montpellier, France, 1995, pp. 21-27.

[28] Cerovic Z.G., Goulas Y., Gorbunov M., Briantais J.-M., Camenen L., Moya I., Fluorosensing of water stress in plants. Diurnal changes of the mean lifetime an yield of chlorophyll fluorescence, measured simultaneously and at distance with a t-LIDAR and a modified PAM-fluorimeter, in maize, sugar beet and Kalancho, Remote Sens. Environ. 58 (1996) 311-321.

[29] Cerovic Z.G., Langrand E., Latouche G., Morales F., Moya I., Spectral characterization of $\mathrm{NAD}(\mathrm{P}) \mathrm{H}$ fluorescence in intact isolated chloroplasts and leaves: Effect of chlorophyll concentration on reabsorption of blue-green fluorescence, Photosynth. Res. 56 (1998) 291-301.

[30] Cerovic Z.G., Morales F., Moya I., Timeresolved spectral studies of blue-green fluorescence of leaves, mesophyll and chloroplasts of sugar beet (Beta vulgaris L.), Biochim. Biophys. Acta 1188 (1994) 58-68.

[31] Chappelle E.W., Special issue of Remote Sensing of Environment, Elsevier, New York, 1994.

[32] Chappelle E.W., McMurtrey J.E., Wood F.M., Newcomb W.W., Laser-induced fluorescence of green plants. 2: LIF caused by nutrient deficiencies in corn, Appl. Opt. 23 (1984) 139-142.

[33] Chappelle E.W., McMurtrey J.E.I., Kim M.S., Identification of the pigment responsible for the blue fluorescence band in the laser induced fluorescence (LIF) spectra of green plants, and the potential use of the band in remotely estimating rates of photosynthesis, Remote Sens. Environ. 36 (1991) 213-218.

[34] Chappelle E.W., Williams D.L., Laser-induced fluorescence (LIF) from plant foliage, IEEE Trans. Geosci. Remote Sens. 25 (1987) 726-736. 
[35] Chappelle E.W., Wood F.M., McMurtrey J.E., Newcomb W.W., Laser-induced fluorescence of green plants. 1: A technique for the remote detection of plant stress and species differentiation, Appl. Opt. 23 (1984) 134-138.

[36] Chappelle E.W., Wood F.M., Newcomb W.W., McMurtrey J.E., Laser-induced fluorescence of green plants. 3: LIF spectral signatures of five major plant types, Appl. Opt. 24 (1985) 74-80.

[37] Chekalyuk A.M., Gorbunov M.Y., Pump-andprobe LIDAR technique: new approach to active biomonitoring of sea and land, in: Guyot G. (Ed.), Physical Measurements and Signatures in Remote Sensing, CNES, Val d'Isère, France, 1994, pp. 915-922.

[38] Chishaki N., Horiguchi T., Response of secondary metabolism in plants to nutrient deficiency, Soil Sci. Plant Nutr. 43 (1997) 987-991.

[39] Corp L.A., McMurtrey J.E., Chappelle E.W., Daughtry C.S.T., Kim M.S., UV band fluorescence (in vivo) and its implications to the remote assessment of nitrogen supply in vegetation, Remote Sens. Environ. 61 (1997) 110-117.

[40] Csintalan Z., Tuba Z., Lichtenthaler H.K., Changes in laser-induced chlorophyll fluorescence ratio F690/F735 in the poikilochlorophyllous desiccation tolerant plant xerophyta scabrida during desiccation, J. Plant Physiol. 152 (1998) 540-544.

[41] Dahn H.G., Günther K.P., Lüdeker W., Characterization of drought stress of maize and wheat canopies by means of spectral resolved laser induced fluorescence, EARSeL Adv. Remote Sens. 1 (1992) 12-19.

[42] Dai G.H., Andary C., Mondolot-Cosson L., Boubals D., Histochemical studies on the interaction between three species of grapevine, Vitis vinifera, $V$. rupestris and $V$. rotundifolia and the downy mildew fungus, Plasmopara viticola, Physiol. Mol. Plant Pathol. 46 (1995) 177-188.

[43] Darvill A.G., Albersheim P., Phytoalexins and their elicitors - A defense against microbial infection in plants, Annu. Rev. Plant Physiol. 35 (1984) 243-275.

[44] Dau H., Molecular mechanisms and quantitative models of variable photosystem II fluorescence, Photochem Photobiol 60 (1994) 1-23.

[45] Day T.A., Howells B.W., Rice W.J., Ultraviolet absorption and epidermal-transmittance spectra in foliage, Physiol. Plant. 92 (1994) 207-218.

[46] Delaveau P., Paris R.R., Répartition, localisation et transport des polyphénols chez les végétaux, J. Pharm. Belg. 27 (1972) 57-70.
[47] DeLucia E.H., Day T.A., Vogelmann T.C., Ultraviolet- $B$ and visible light penetration into needles of two species of subalpine conifers during foliar development, Plant Cell Environ. 15 (1992) 921-929.

[48] Der Nigohossian G., Les lasers aux laboratoires. Conseils pratiques de prevention protection, Commissariat à l'Energie Atomique, 1988.

[49] Determann S., Reuter R., Wagner P., Willkomm R., Fluorescent matter in the eastern Atlantic Ocean. Part 1: method of measurement and near-surface distribution, Deep-Sea Res. I 41 (1994) 659-675.

[50] Dixon R.A., Paiva N.L., Stress-induced phenylpropanoid metabolism, Plant Cell 7 (1995) 1085-1097.

[51] Edner H., Johansson J., Svanberg S., Lichtenthaler H.K., Lang M., Stober F., Schindler C., Björn L.O., Remote multi-color fluorescence imaging of selected broad-leaf plants, EARSeL Adv. Remote Sens. 3 (1995) 2-14.

[52] Edner H., Johansson J., Svanberg S., Wallinder E., Fluorescence lidar multicolor imaging of vegetation, Appl. Optics 33 (1994) 2471-2479.

[53] Edner H., Johansson J., Svanberg S., Wallinder E., Bazzani M., Breschi B., Cecchi G., Pantani L., Radicati B., Raimondi V., Tirelli D., Valmori G., Mazzinghi P., Laser-induced fluorescence monitoring of vegetation in Tuscany, EARSeL Adv. Remote Sens. 1 (1992) 119-130.

[54] Esau K., Plant Anatomy, John Wiley \& Sons, New York, 1953.

[55] Foyer C., Furbank R., Harbinson J., Horton P., The mechanisms contributing to photosynthetic control of electron transport by carbon assimilation in leaves, Photosynth. Res. 25 (1990) 83-100.

[56] Genty B., Briantais J., Baker N., The relationship between the quantum yield of photosynthetic electron transport and quenching of chlorophyll fluorescence, Biochim Biophys Acta 990 (1989) 87-92.

[57] Genty B., Wonders J., Baker N.R., Non-photochemical quenching of Fo in leaves is emission wavelength dependent: consequences for quenching analysis and its interpretation, Photosynth. Res. 26 (1990) 133-139.

[58] Gitelson A.A., Buschmann C., Lichtenthaler H.K., Leaf chlorophyll fluorescence corrected for reabsorption by means of absorption and reflectance measurements, J. Plant Physiol. 152 (1998) 283-296.

[59] Goulas Y., Camenen L., Guyot G., Cerovic Z.G., Briantais J.-M., Schmuck G., Moya I., Measurements of laser-induced fluorescence decay and 
reflectance of plant canopies, Remote Sens. Rev. 15 (1997) 305-322.

[60] Goulas Y., Moya I., Schmuck G., Time-resolved spectroscopy of the blue fluorescence of spinach leaves, Photosynth. Res. 25 (1990) 299-307.

[61] Govindjee, Sixty-three years since Kautsky: chlorophyll a fluorescence, Aust. J. Plant Physiol. 22 (1995) 131-160.

[62] Günther K.P., Dahn H.-G., Lüdeker W., Remote sensing vegetation status by laser-induced fluorescence, Remote Sens. Environ. 47 (1994) 10-17.

[63] Günther K.P., Lüdeker W., Dahn H.-G., Design and testing of a spectral-resolving fluorescence LIDAR system for remote sensing of vegetation, in: Hunt J.J. (Ed.), Proc. 5th Int. Coll. of Physical Measurements and Signatures in Remote Sensing, ESA SP-319, Courchevel, France, 1991, pp. 723-726.

[64] Günther K.P., Schmuck G., Final report of the EUREKA project LASFLEUR (EU380): Remote sensing of vegetation by laser induced chlorophyll fluorescence, 1993.

[65] Guyot G., Physical Measurements and Signatures in Remote Sensing, CNES, Val d'Isère, France, 1994.

[66] Guyot G., Photosynthesis and Remote Sensing, EARSeL, Paris, Montpellier, France, 1995.

[67] Hall A.E., Physiological ecology of crops in relation to light, water, and temperature, in: Carroll C.R., Vandermeer J.H., Rosset P. (Eds.), Agroecology, McGraw Hill, New York, 1990, pp. 191-234.

[68] Harborne J.B., The flavonoids: recent advances, in: Goodwin T.W. (Ed.), Plant Pigments, Academic Press, London, 1988, pp. 299-343.

[69] Harris P.J., Hartley R.D., Detection of bound ferulic acid in the cell walls of the Gramineae by ultraviolet fluorescence microscopy, Nature 259 (1976) 508-510.

[70] Harris P.J., Hartley R.D., Phenolic constituents of the cell walls of monocotyledons, Biochem. Syst. Ecol. 8 (1980) 153-160.

[71] Hartley R., Harris P., Phenolic constituents of the cell walls of dicotyledons, Biochem. Syst. Ecol. 9 (1981) 189-203.

[72] Hartman F.C., Harpel M.R., Structure, function, regulation, and assembly of D-ribulose-1,5-bisphosphatecarboxylase/oxygenase, Annu. Rev. Biochem. 63 (1994) 197-234.

[73] Heisel F., Sowinska M., Miehe J.A., Lang M., Lichtenthaler H.K., Detection of nutrient deficiencies of maize by laser induced fluorescence imaging, J. Plant Physiol. 148 (1996) 622-631.

[74] Hoge F.E., Swift R.N., Airborne dual laser excitation and mapping of phytoplankton photopigments in a Gulf Stream Warm Core Ring, Appl. Opt. 22 (1983) 2271-2281.

[75] Hoge F.E., Swift R.N., Yungel J.K., Feasibility of airborne detection of laser induced emissions from green terrestrial plants, Appl. Opt. 22 (1983) 2991-3000.

[76] Ishii T., Structure and function of feruloylated polysaccharides, Plant Sci. 127 (1997) 111-127.

[77] Johansson J., Andersson M., Edner H., Mattsson J., Svanberg S., Remote fluorescence measurements of vegetation spectrally resolved and by multi-colour fluorescence imaging, J. Plant Physiol. 148 (1996) 632-637.

[78] Joshi M.K., Mohanty P., Probing photosynthetic performance by chlorophyll $a$ fluorescence: analysis and interpretation of fluorescence parameters, J. Sci. Ind. Res. India 54 (1995) 155-174.

[79] Kim H.H., New algae mapping technique by use of an airborne laser fluorosensor, Appl. Opt. 12 (1973) 1454-1459.

[80] Kim H.H., Brown K.S., Laser and sunlightinduced fluorescence from chlorophyll pigments, in: IGARSS '86, ESA Publication Division, Zurich, 1986, pp. 1599-1601.

[81] Kim M.S., Krizek D., Daughtry C.S.T., McMurtrey J.E., Sandhu R., Chappelle E.W., Corp L.A., Middleton E., Fluorescence imaging system: application for the assessment of vegetation stresses, in: Cecchi G., D'Urso G., Engman E.T., Gudmansen P. (Eds.), Remote Sensing of Vegetation and Sea (EUROPTO '96), SPIE, Taormina, Italy, 1996, pp. 4-13.

[82] Kim M.S., Lee E.H., Mulchi C.L., McMurtrey J.E., Chappelle E.W., Rowland R.A., Fluorescence imaging of soybean flavonol isolines, in: Advances in Laser Remote Sensing for Terrestrial and Oceanographic Applications, SPIE, 1998, in press.

[83] Knogge W., Weissenböck G., Tissue-distribution of secondary phenolic biosynthesis in developing leaves of Avena sativa L., Planta 167 (1986) 196-205.

[84] Kobayashi T., Techniques for laser remote sensing of the environment, Remote Sens. Rev. 3 (1987) $1-58$.

[85] Koch W., Wagner C., Seitz H., Elicitor-induced cell death and phytoalexin synthesis in Daucus carota L., Planta 206 (1998) 523-532. 
[86] Konig K., Simon U., Halbhuber K.J., 3D resolved two-photon fluorescence microscopy of living cells using a modified confocal laser scanning microscope, Cell. Mol. Biol. 42 (1996) 1181-1194.

[87] Konschin H., Sundholm F., Sundholm G., Fluorescence characteristics of lignin model compounds. I. Styrene derivatives, Acta Chem. Scand. B. 30 (1976) 262-266.

[88] Krause G., Weis E., Chlorophyll fluorescence and photosynthesis: The basics, Annu. Rev. Plant Physiol. Plant Mol. Biol. 42 (1991) 313-349.

[89] Lang M., Lichtenthaler H.K., Changes in the blue-green and red fluorescence-emission spectra of beach leaves during the autumnal chlorophyll breakdown, J. Plant Physiol. 138 (1991) 550-553.

[90] Lang M., Lichtenthaler H.K., Sowinska M., Heisel F., Miehe J.A., Fluorescence imaging of water and temperature stress in plant leaves, J. Plant Physiol. 148 (1996) 613-621.

[91] Lang M., Lichtenthaler H.K., Sowinska M., Summ P., Heisel F., Blue, green and red fluorescence signatures and images of tobacco leaves, Bot. Acta 107 (1994) 230-236.

[92] Lang M., Siffel P., Braunova Z., Lichtenthaler H.K., Investigations of the blue-green fluorescence emission of plant leaves, Bot. Acta 105 (1992) 435-440.

[93] Lang M., Stober F., Lichtenthaler H.K., Fluorescence emission spectra of plant leaves and plant constituents, Radiat. Environ. Biophys. 30 (1991) 333-347.

[94] Lichtenthaler H., Miehé J., Fluorescence imaging as a diagnostic tool for plant stress, Trends Plant Sci. 2 (1997) 316-320.

[95] Lichtenthaler H.K., Applications of Chlorophyll Fluorescence in Photosynthesis Research, Stress Physiology, Hydrobiology and Remote Sensing, Kluwer Academic Publisher, Dordrecht, 1988.

[96] Lichtenthaler H.K., Vegetation stress, Gustav Fischer, Stuttgart, 1996.

[97] Lichtenthaler H.K., Buschmann C., Rinderle U., Schmuck G., Application of chlorophyll fluorescence in ecophysiology, Radiat. Environ. Biophys. 25 (1986) 297-308.

[98] Lichtenthaler H.K., Lang M., Sowinska M., Heisel F., Miehé J.A., Detection of vegetation stress via a new high resolution fluorescence imaging system, $\mathbf{J}$. Plant Physiol. 148 (1996) 599-612.

[99] Lichtenthaler H.K., Lang M., Sowinska M., Summ P., Heisel F., Miehe J.A., Uptake of the herbicide diuron as visualized by the fluorescence imaging technique, Bot. Acta 110 (1997) 158-163.

[100] Lichtenthaler H.K., Lang M., Stober F., Nature and variation of blue fluorescence spectra of terrestrial plants, in:, Int. Geoscience and Remote Sensing Symposium, IGARSS '91, Helsinki University of Technology, Espoo, 1991, pp. 2283-2286.

[101] Lichtenthaler H.K., Rinderle U., The role of chlorophyll fluorescence in the detection of stress conditions in plants, CRC Crit. Rev. Anal. Chem. 19 (1988) 29-85.

[102] Lichtenthaler H.K., Schweiger J., Cell wall bound ferulic acid, the major substance of the bluegreen fluorescence emission of plants, J. Plant Physiol. 152 (1998) 272-282.

[103] Lichtenthaler H.K., Subhash N., Wenzel O., Miehé J.A., Laser-induced imaging of blue/red and blue/far-red fluorescence ratios, F440/F690 and F440/F740, as a means of early stress detection in plants, in: Proc. Int. Geoscience and Remote Sensing Symposium, IGARSS '97, IEEE/USA, Singapore, 1997, pp. 1799-1801.

[104] Lichtenthaler H.K., Wenzel O., Buschmann C., Gitelson A., Plant stress detection by reflectance and fluorescence, Ann. N.Y. Acad. Sci. 851 (1998) 271-285.

[105] Liu L., Gitz III D.C., McClure J.W., Effects of UV-B on flavonoids, ferulic acid, growth and photosynthesis in barley primary leaves, Physiol. Plant. 93 (1995) 725-733.

[106] Liu L., McClure J., Effects of UV-B on activities of enzymes of secondary phenolic metabolism in barley primary leaves, Physiol. Plant. 93 (1995) 734-739.

[107] Lüdeker W., Dahn H.-G., Günther K.P., Detection of fungal infection of plants by laser-induced fluorescence: An attempt to use remote sensing, J. Plant Physiol. 148 (1996) 579-585.

[108] Lüdeker W., Günther K.P., Dahn H.-G., Comparison of different detection set-ups for laserinduced fluorescence monitoring of vegetation, EARSeL Adv. Remote Sens. 3 (1995) 32-41.

[109] McMurtray J.E.I., Chappelle E.W., Kim M.S., Meisinger J.J., Corp L.A., Distinguishing nitrogen fertilization levels in field corn (Zea mays L.) with actively induced fluorescence and passive reflectance measurements, Remote Sens. Environ. 47 (1994) 36-44.

[110] Middleton E., Chappelle E.W., DeLuca A., Evaluating photosynthesis in boreal forest species with fluorescence measurements, in: International 
Geoscience and Remote Sensing Symposium (IGARSS '95), Firenze, Italy, 1995, pp. 1723-1725.

[111] Middleton E.M., Chappelle E.W., Cannon T.A., Adamse P., Britz S.J., Initial assessment of physiological response to UV-B irradiation using fluorescence measurements, J. Plant Physiol. 148 (1996) 69-77.

[112] Mohammed G.H., Binder W.D., Gillies S.L., Chlorophyll fluorescence: a review of its practical forestry applications and instrumentation, Scand. J. For. Res. 10 (1995) 383-410.

[113] Morales F., Belkhodja R., Goulas Y., Abad'a J., Moya I., Remote and near-contact chlorophyll fluorescence during photosynthetic induction in iron-deficient sugar beet leaves, Remote Sens. Environ. (1999) in press.

[114] Morales F., Cerovic Z.G., Moya I., Characterization of blue-green fluorescence in the mesophyll of sugar beet (Beta vulgaris L.) leaves affected by iron deficiency, Plant Physiol. 106 (1994) 127-133.

[115] Morales F., Cerovic Z.G., Moya I., Timeresolved blue-green fluorescence of sugar beet (Beta vulgaris L.) leaves: Spectroscopic evidence for the presence of ferulic acid as the main fluorophore in the epidermis, Biochim. Biophys. Acta 1273 (1996) 25I-262.

[116] Morales F., Cerovic Z.G., Moya I., Timeresolved blue-green fluorescence of sugar beet leaves. Temperature-induced changes and consequences for the potential use of blue-green fluorescence as a signature for remote sensing of plants, Aust. J. Plant Physiol. 25 (1998) 325-334.

[117] Morrison T.A., Jung H.G., Buxton D.R., Hatfield R.D., Cell-wall composition of maize internodes of varying maturity, Crop Sci. 38 (1998) 455-460.

[118] Moya I., Durée de vie et rendement de fluorescence de la chlorophylle in vivo. Leur relation dans differents modeles d'unites photosynthètique, Biochim. Biophys. Acta 368 (1974) 214-227.

[119] Moya I., Goulas Y., Morales F., Camenen L., Guyot G., Schmuck G., Remote sensing of timeresolved chlorophyll fluorescence and back-scattering of the laser excitation by vegetation, EARSeL Adv. Remote Sens. 3 (1995) 188-197.

[120] Moya I., Guyot G., Goulas Y., Remotely sensed blue and red fluorescence emission for monitoring vegetation, ISPRS J. Photogram. Remote Sens. 47 (1992) 205-231.

[121] Moya I., Sebban P., Haehnel W., Lifetime of excited states and quantum yield of chlorophyll $a$ fluorescence in vivo, in: Govindjee, Amesz J., Fork D.C.
(Eds.), Light Emission by Plants and Bacteria, Academic Press, Orlando, 1986, pp. 161-190.

[122] Niemann G.J., van der Kerk A., Niessen W.M.A., Versluis K., Free and cell wall-bound phenolics and other constituents from healthy and fungusinfected carnation (Dianthus caryophyllus L.) stems, Physiol. Mol. Plant Pathol. 38 (1991) 417-432.

[123] Nilsson H.-E., Remote sensing and image analysis in plant pathology, Can. J. Plant Pathol. 17 (1995) 154-166.

[124] O'Neil R.A., Buja-Bujunas L., Rayner D.N., Field performance of a laser fluorosensor for the detection of oil spills, Appl. Opt. 19 (1980) 863-870.

[125] Ögren E., Baker N.R., Evaluation of a technique for the measurement of chlorophyll fluorescence from leaves exposed to continuous white light, Plant Cell Environ. 8 (1985) 539-547.

[126] Papageorgiou G., Chlorophyll fluorescence: an intrinsic probe of photosynthesis, in: Govindjee (Ed.), Bioenergetics of Photosynthesis, Academic Press, New York, 1975, pp. 319-371.

[127] Pfundel E., Estimating the contribution of Photosystem I to total leaf chlorophyll fluorescence, Photosynth. Res. 56 (1998) 185-195.

[128] Philpot W., Duggin M., Raba R., Tsai F.-A., Analysis of reflectance and fluorescence spectra for atypical features: fluorescence in yellow-green, J. Plant Physiol. 148 (1996) 567-573.

[129] Price P., Waring G.L., Julkunen-Titto R., Tahvanainen J., Mooney H.A., Craig T., Carbon-nutrient balance hypothesis in within-species phytochemical variation of Salix lasiolepis, J. Chem. Ecol. 15 (1989) 1117-1131.

[130] Rabinowitch E.I., Photosynthesis and Related Processes, Interscience, New York, 1951.

[131] Renger G., Schreiber U., Practical applications of fluorometric methods to algae and higher plant research, in: Govindjee, Amesz J., Fork D.C. (Eds.), Light Emission by Plants and Bacteria, Academic Press, Orlando, 1986, pp. 587-619.

[132] Reuber S., Bornman J.F., Weissenbock G., Phenylpropanoid compounds in primary leaf tissues of rye (Secale cereale). Light response of their metabolism and the possible role in UV-B protection, Physiol. Plant. 97 (1996) 160-168.

[133] Ribéreau-Gayon P., Les composés phénoliques des végétaux, Dunod, Paris, 1968.

[134] Saito Y., Hatake K., Nomura E., Kawahara T.D., Nomura A., Sugimoto N., Itabe T., Range- 
resolved image detection of laser-induced fluorescence of natural trees for vegetation distribution monitoring, Jpn. J. Appl. Phys. 36 (1997) 7024-7027.

[135] Saito Y., Kanoh M., Hatake K., Kawahara T.D., Nomura A., Investigation of laser-induced fluorescence of several natural leaves for application of lidar vegetation monitoring, Appl. Optics 37 (1998) 431-437.

[136] Saito Y., Kanoh M., Takeuchi A., Kawahara T.D., Nomura A., Ishizawa H., Matsuzawa T., Komatsu K., Application of laser-induced fluorescence to growth monitoring of agricultural products (lettuce), in: First International Conference on Geospatial Information in Agriculture and Forestry, Lake Buena Vista, Florida, 1998, pp. 509-515.

[137] Saito Y., Takahashi K., Nomura E., Mineuchi K., Kagawa T.D., Nomura A., Kobayashi S., Ishii H., Visualization of laser-induced fluorescence of plants influenced by environmental stress with a microfluorescence imaging system and a fluorescence imaging lidar system, in: Narayanan R.M., Kalshoven J.E. (Eds.), Advances in Laser Remote Sensing for Terrestrial and Oceanographic Applications, SPIE, 1997, pp. 190-198.

[138] Sandhu R., Kim M.S., Krizek D.T., Middleton E., Fluorescence imaging and chlorophyll fluorescence to evaluate the role of EDU in UV-B protection in cucumber, in: Aerosense '97, SPIE, 1997, pp. 42-50.

[139] Schmuck G., Moya I., Pedrini A., Vanderlinde D., Lichtenthaler H.K., Stober F., Schindler C., Goulas Y., Chlorophyll fluorescence lifetime determination of water-stressed C3-plant and C4-plant, Radiat. Environ. Biophys. 31 (1992) 141-151.

[140] Schneckenburger H., Frenz M., Time-resolved fluorescence of conifers exposed to environmental pollutants, Radiat. Environ. Biophys. 25 (1986) 289-295.

[141] Schreiber U., Bilger W., Progress in chlorophyll fluorescence research: major developments during the past years in retrospect, in: Progress in Botany, Springer Verlag, Berlin, Heildelberg, 1993, pp. 151-173.

[142] Schreiber U., Bilger W., Neubauer C., Chlorophyll fluorescence as a noninvasive indicator for rapid assessment of in vivo photosynthesis, in: Schulze E.D., Caldwell M.M. (Eds.), Ecophysiology of Photosynthesis, Springer-Verlag, Berlin, 1994, pp. 49-70.

[143] Schreiber U., Neubauer C., Schliwa U., PAM fluorometer based on medium-frequency pulsed $\mathrm{Xe}$ flash measuring light: A highly sensitive new tool in basic and applied photosynthesis research, Photosynth. Res. 36 (1993) 65-72.
[144] Schreiber U., Schliwa U., Bilger W., Continuous recording of photochemical and non-photochemical chlorophyll fluorescence quenching with a new type of modulation fluorimeter, Photosynth. Res. 10 (1986) 51-62.

[145] Schweiger J., Lang M., Lichtenthaler H.K., Differences in fluorescence excitation spectra of leaves between stressed and non-stressed plants, J. Plant Physiol. 148 (1996) 536-547.

[146] Sheahan J.J., Sinapate esters provide greater UV-B attenuation than flavonoids in Arabidopsis thaliana (Brassicaceae), Am. J. Bot. 83 (1996) 679-686.

[147] Sowinska M., Heisel F., Miehe J.A., Lang M., Lichtenthaler H.K., Tomasini F., Remote sensing of plants by streak camera lifetime measurements of the chlorophylla emission, J. Plant Physiol. 148 (1996) 638-644.

[148] Sparvoli F., Martin C., Scienza A., Gavazzi G., Tonelli C., Cloning and molecular analysis of structural genes involved in flavonoid and stilbene biosynthesis in grape (Vitis vinifera L.), Plant Mol. Biol. 24 (1994) 743-755.

[149] Stafford H.A., Anthocyanins and betalains: evolution of mutually exclusive pathways, Plant Sci. 101 (1994) 91-98.

[150] Stober F., Lang M., Lichtenthaler H.K., Blue, green, and red fluorescence emission signatures of green, etiolated, and white leaves, Remote Sens. Environ. 47 (1994) 65-71.

[151] Stober F., Lichtenthaler H.K., Changes of the laser-induced blue, green and red fluorescence signatures during greening of etiolated leaves of wheat, J. Plant Physiol. 140 (1992) 673-680.

[152] Stober F., Lichtenthaler H.K., Characterization of the laser-induced blue, green and red fluorescence signatures of leaves of wheat and soybean grown under different irradiance, Physiol. Plant. 88 (1993) 696-704.

[153] Stober F., Lichtenthaler H.K., Studies on the constancy of the blue and green fluorescence yield during the chlorophyll fluorescence induction kinetics (Kautsky effect), Radiat. Environ. Biophys. 32 (1993) 357-365.

[154] Stober F., Lichtenthaler H.K., Studies on the localization and spectral characteristics of the fluorescence emission of differently pigmented wheat leaves, Bot. Acta 106 (1993) 365-370.

[155] Subhash N., Detection of vegetation stress from laser-induced fluorescence signatures, International Centre for Theoretical Physics, 1995. 
[156] Subhash N., Mazzinghi P., Agati G., Fusi F., Lercari B., Analysis of laser-induced fluorescence line shape of intact leaves: application to UV stress detection, Photochem. Photobiol. 62 (1995) 711-718.

[157] Svanberg S., Fluorescence lidar monitoring of vegetation status, Physica Scr. 58 (1995) 79-85.

[158] Takahashi K., Mineuchi K., Nakamura T., Sakurai N., Komatsu A., Koizumi M., Kano H., Laser induced fluorescence of tree leaves: spectral changes with plant species and seasons, in: International Geoscience and Remote Sensing Symposium IGARSS '93, Institute of Electrical and Electronic Engineers, New York, 1993, 1985-1987.

[159] Takahashi K., Nakamura T., Emori Y., Kimura A., Light-induced fluorescence of in-vivo chlorophyll of a rice plant - a technique for the remote detection of plant growth, in: Guyenne T.D., Hunt J.J. (Eds.), 4th Int. Coll. on Spectral Signatures of Objects in Remote Sensing, ESA SP-287, Aussois, France, 1988, pp. 255-258.

[160] Theisen A.F., Fluorescence changes of a drying maple leaf observed in the visible and near-infrared, in: Lichtenthaler H.K. (Ed.), Applications of Chlorophyll Fluorescence in Photosynthesis Research, Stress Physiology, Hydrobiology and Remote Sensing, Kluwer Academic Publisher, Dordrecht, 1988, pp. 197-201.

[161] Tissut M., Ravanel P., Répartition des flavonols dans l'épaisseur des feuilles de quelques végétaux vasculaires, Phytochemistry 19 (1980) 2077-2081.

[162] Tronchet J., Essai de localisation des substances flavonoïques dans l'épaisseur des limbes de Bryophyllum crenatum Bak., à divers stades de leur développement, C.R. Acad. Sci. Paris 266 (1968) 882-884.

[163] Valentini R., Cecchi G., Mazzinghi P., Scarascia-Mugnozza G., Agati G., Bazzani M., De
Angelis P., Fusi F., Matteucci G., Raimondi V., Remote sensing of chlorophyll $a$ fluorescence of vegetation canopies: 2. Physiological significance of fluorescence signal in response to environmental stresses, Remote Sens. Environ. 47 (1994) 29-35.

[164] Van Kooten O., Snel J.F.H., The use of chlorophyll fluorescence nomenclature in plant stress physiology, Photosynth. Res. 25 (1990) 147-150.

[165] van Vokenburgh E., Leaf and shoot growth, in: Physiology and Determination of Crop Yield, American Society of Agronomy, Madison WI, 1994, pp. 101-125.

[166] Veit M., Bilger T., Muhlbauer T., Brummet W., Winter K., Diurnal changes in flavonoids, J. Plant Physiol. 148 (1996) 478-482.

[167] Velick S.F., in: McElroy W.D., Glass B. (Ed.), Light and Life, Johns Hopkins Press, Baltimore, Maryland, 1961, pp. 108-143.

[168] Vos J., van der Putten P.E.L., Effect of nitrogen supply on leaf growth, leaf nitrogen economy and photosynthetic capacity in potato, Field Crops Res. 59 (1998) 63-72.

[169] Waterman P.G., Mole S., Analysis of Phenolic Plant Metabolites, Blackwell Scientific Publications, Oxford, 1994.

[170] Weissenböck G., Schnabl H., Sachs G., Elbert C., Heller F.-O., Flavonol content of guard cell and mesophyll cell protoplasts isolated from Vicia faba leaves, Physiol. Plant. 62 (1984) 356-362.

[171] Wolfbeis O.S., The fluorescence of organic natural products, in: S.G. Schulman (Ed.), Molecular Luminescence Spectroscopy. Methods and Applications: Part 1, John Wiley \& Sons, New York, 1985, pp. 167-370.

[172] Wollenweber E., Dietz V.H., Occurrence and distribution of free flavonoid aglycones in plants, Phytochemistry 20 (1981) 869-932. 